\title{
Synthesis, molecular docking and QSAR studies of 2, 4-disubstituted thiazoles as antimicrobial agents
}

\author{
Preeti Arora ${ }^{1}$, Rakesh Narang ${ }^{1 *}$, Sonam Bhatia ${ }^{1}$, Surendra Kumar Nayak ${ }^{1}$, Sachin Kumar Singh ${ }^{1}$, Balasubramanian \\ Narasimhan $^{2}$ \\ ${ }^{1}$ Department of Pharmaceutical Chemistry, School of Pharmaceutical Sciences, Lovely Professional University, Phagwara-144401, India. \\ ${ }^{2}$ Faculty of Pharmaceutical Sciences, Maharshi Dayanand University, Rohtak-124001, India.
}

\begin{tabular}{|c|c|}
\hline ARTICLE INFO & ABSTRACT \\
\hline Article history: & \multirow{7}{*}{$\begin{array}{l}\text { In present study a series of 2,4-disubstituted thiazole derivatives was synthesized and evaluated for their in vitro } \\
\text { antibacterial and antifungal activities against } B \text {. subtilis, E. coli, } S \text {. aureus, C. albicans and A. niger by tube } \\
\text { dilution method. The analysis of antimicrobial activity results indicated that the presence of } \mathrm{NO}_{2} \text { and } \mathrm{OCH}_{3} \\
\text { groups at para position of phenyl group improved the antimicrobial activity significantly. Molecular docking } \\
\text { studies also supported in vitro activity results and showed that } \mathrm{NO}_{2} \text { and } \mathrm{OCH}_{3} \text { groups containing compounds } \\
\text { have greater affinity towards the target glucosamine- } 6-\mathrm{phosphate} \mathrm{synthase.} \mathrm{QSAR} \mathrm{studies} \mathrm{indicated} \mathrm{that} \\
\text { molecular connectivity index }\left({ }^{2} \chi^{\mathrm{v}}\right) \text { and Kier's shape index }\left(\mathrm{Ka}_{3}\right) \text { are the key parameters for antimicrobial activity } \\
\text { of synthesized thiazole derivatives and can be cosidered as important factors for interaction with target site of } \\
\text { different microorganisms. It is pertinent to note that multi-target QSAR models were more effectual in } \\
\text { demonstrating the antimicrobial activity than one-target QSAR models. }\end{array}$} \\
\hline Received on: 13/11/2014 & \\
\hline Revised on: 04/12/2014 & \\
\hline Accepted on: $22 / 01 / 2015$ & \\
\hline Available online: $27 / 02 / 2015$ & \\
\hline Key words: & \\
\hline $\begin{array}{l}\text { Antimicrobial, antifungal, } \\
\text { antibacterial, 2,4-disbutituted } \\
\text { thiazole, docking, QSAR. }\end{array}$ & \\
\hline
\end{tabular}

\section{INTRODUCTION}

The treatment of infectious diseases caused by bacteria, parasites, viruses and fungi always remains a global health problem because of increasing number of multi-drug resistant pathogenic microbial strains (Narang et al., 2012). Despite the availability of large number of antibiotics for clinical use, the emergence of antibiotic resistance in recent years against Grampositive and Gram-negative bacterial and fungal strains constitutes an urgent need for the discovery of new class of antimicrobial agents (Perez et al., 2014; Narasimhan et al., 2009). Various sulfur and/or nitrogen containing heterocyclics belonging to the class of alkaloids, vitamins, pigments etc. possessing biological activities are reported in the literature (Ozdemir et al., 2007). 1,3-thiazoles and their derivatives are important class of five membered heterocyclic compounds having sulphur and nitrogen at position-1 and -3 , respectively.

* Corresponding Author

Rakesh Narang, Department of Pharmaceutical Chemistry, School of

Pharmaceutical Sciences, Lovely Professional University, Phagwara-

144401, India.Email: rakesh_nrng@yahoo.co.in 1,3-thiazoles derivatives have been reported to possess wide range of biological activities like antibacterial (Bharti et al., 2010), antifungal (Bharti et al., 2010), antiviral (El-Sabbagh et al., 2009), anti-inflammatory (Helal et al., 2013), anticancer (Soares et al., 2013), antitubercular (Mjambili et al., 2014), antiplasmodial (Mjambili et al., 2014), antiallergic (Ban et al., 1998), antiinflammatory (Ben et al., 1998), antipsychotropic (Zablotskaya et al., 2013), antiarthritic (Nishikaku et al., 1993) etc. 1,3-thiazole nucleus is commonly found in the chemical structures of antiparasitic agents viz. nitazoxanide, aminitrozole and tenonitrozole (Cohen et al., 2012). Morover, penicillin derivatives (antibacterial) (Ye et al., 2013), vitamin $\mathrm{B}_{1}$ (thiamine) (Wei et al., 2014), bleomycin (Rahmutulla et al., 2014) and tiazofurin (antineoplastic) (Popsavin et al., 2006), ritonavir (anti-HIV) (Sevrioukova et al., 2013), fanetizole (Styrt et al., 1985) and meloxicam (anti-inflammatory) (Novakova et al., 2014), nizatidine (antiulcer) (Jain et al., 2014) are also thiazole ring containing important biologically active agents. Structure activity relationship study of thiazole based drugs/leads revealed that substituents on a particular position specifically at position 2 and 4 of the 1,3thiazole ring affect the biological outcomes to a great extent. 
Molecular docking is a computer-assisted drug design (CADD) method used to predict the favourable orientation of a ligand (viz. drug) to a target (viz. receptor) when bound to each other to form a stable complex. By understanding of the favoured orientation in turn can be used to find out the strength of binding affinity between ligand and target site, e.g. by docking score (Sarojini et al., 2010). Moreover, docking study can be used to find out type of interactions between ligand and receptor viz. hydrogen bonding and hydrophobic interactions.

Hence, molecular docking can be considered as first-line technique for a pharmaceutical lead discovery (Shoichet et al., 2002). Moreover, in silico studies on 2,5-dichloro thienyl substituted thiazole derivatives carried out by the research group of Sarojini and co-workers (2010) have found that thiazole based analogues have potential to bind with the enzyme, L-glutamine: D-fructose -6 -phosphate amidotransferase.

This enzyme is commonly known by the trivial name of glucosamine-6-phosphate synthase (EC 2.6.1.16), which is characterized as a new antifungal target (Chmara et al., 1984; Chmara et al., 1986, Milewski et al., 1988). This enzyme carries out transferase reaction which involves the transfer of ammonia group from L-glutamine to fructose-6-phosphate (Fru-6-P), which is followed by isomerisation of fructosamine-6-phosphate to glucosamine-6-phosphate (Dutka-Malen et al., 1988; Bates et al., 1966).

This reaction is involved in the formation of uridine diphosphate $\mathrm{N}$-acetylglucosamine (UDP-GlcNAc), a product that is present in all class of organisms, but in case of fungi and bacteria it is solely used to build macromolecules related with cell wall assembly, e.g. chitins and mannoproteins in case of fungi and peptidoglycan in bacteria. Hence, the target glucosamine-6phosphate synthase was selected for performing the in silico studies in present study. Quantitative structure-activity relationship (QSAR) is a significant part of chemometrics used to correlate experimentally determined biological activities with structural descriptors of chemical compounds (Hansch et al., 1964).

The derived QSAR model can be further utilized to predict biological activity of compound not synthesized in the laboratory (Narang et al., 2013). In light of above facts and in continuation of our research program focused on design and synthesis of novel antimicrobial agents an attempt has been made to synthesize 2,4-disubstituted thiazole derivatives and screened them for in vitro antibacterial and antifungal activities (Narang et al., 2013; Narang et al., 2012; Narang et al., 2011; Kumar et al., 2010; Kumar et al., 2009). Further, to evaluate the active site interaction made by the synthesized compounds, molecular docking studies were carried out which is followed by 2D -QSAR studies to estimate the key descriptors that govern the antimicrobial activity of the compounds under investigation.

\section{MATERIAL AND METHODS \\ Experimental}

Melting points of synthesized compounds were determined in open glass capillaries on a sonar melting point apparatus and are uncorrected. Reaction progress was monitored by thin layer chromatography on silica gel sheets (Merck silica gel-G). ${ }^{1} \mathrm{H}$ Nuclear magnetic resonance $\left({ }^{1} \mathrm{H}\right.$ NMR) spectra were recorded on Bruker Avance II $400 \mathrm{NMR}$ spectrometer $(400 \mathrm{MHz})$ at $298 \mathrm{~K}$, in appropriate deuterated dimethyl sulfoxide. Chemical shifts were reported as $\delta$ (ppm) relative to tetramethylsilane (TMS) as internal standard. Infrared (IR) spectra were recorded as $\mathrm{KBr}$ pellet on Perkin Elmer FTIR spectrometer. The wave number is given in $\mathrm{cm}^{-1}$.

\section{General procedure for synthesis of 2-amino-4-phenylthiazole derivatives (3-12, Scheme 1 and 2) \\ Synthesis of 2-amino-4-phenylthiazole $(2,10)$}

To a mixture of acetophenone/ $p$-nitroacetophenone $(0.1$ $\mathrm{mol})$ and thiourea $(0.2 \mathrm{~mol})$ in absolute ethanol, bromine $(0.2 \mathrm{~mol})$ was added dropwise. After complete addition of bromine, reaction mixture was refluxed on a water-bath for $24 \mathrm{hrs}$. Then water was added to reaction mixture and heated until most of the solid was dissolved. The reaction mixture was filtered while hot. The filtrate was cooled and made alkaline using $20 \%$ ammonium hydroxide to obtain corresponding crude precipitate of 2-amino-4phenylthiazole derivatives ( 2 and 10). Recrystallization from ethanol yielded the corresponding required product.

\section{Synthesis of N-(4-phenyl-thiazol-2-yl)-benzamide/amide derivatives (3-7 and 11-12)}

Acid chloride was prepared by refluxing corresponding acid $(0.01 \mathrm{~mol})$ with distilled thionyl chloride $(0.178 \mathrm{~mol})$ for 3-4 hrs. Excess of thionyl chloride was removed by distillation and synthesized acid chloride was used immediately for next step. The solution of corresponding acid chloride $(0.002 \mathrm{~mol})$ was added dropwise into solution of 2-amino-4-phenylthiazole/4-(4-nitrophenyl)-thiazol-2-ylamine, $(\mathbf{2} / \mathbf{1 0})(0.001 \mathrm{~mol})$ in dry pyridine, and stirred the reaction mixture at $0-10{ }^{\circ} \mathrm{C}$ for $4-5 \mathrm{~h}$. The mixture was allowed to stand overnight at room temperature. The solid precipitates of $N$-(4-phenyl-thiazol-2-yl)-benzamide/amide derivatives (3-7 and 11-12) were obtained, filtered and washed successively using dilute hydrochloric acid, $10 \%$ sodium bicarbonate solution and water subsequently, to remove the residual reactants.

\section{Synthesis of 3,4-dimethoxy-benzylidene-4-phenyl-thiazol-2-yl- amine (8)}

A mixture of 2-amino-4-phenyl thiazole, 3 (0.001 mol) and veratraldehyde $(0.001 \mathrm{~mol})$ in absolute ethanol was refluxed in presence of 2-3 drops of acetic acid for $7 \mathrm{hrs}$. After cooling solid precipitates of (3,4-dimethoxy-benzylidene)-(4-phenyl-thiazol-2yl)-amine was obtained and crude precipitates were recrystallized from ethanol. 


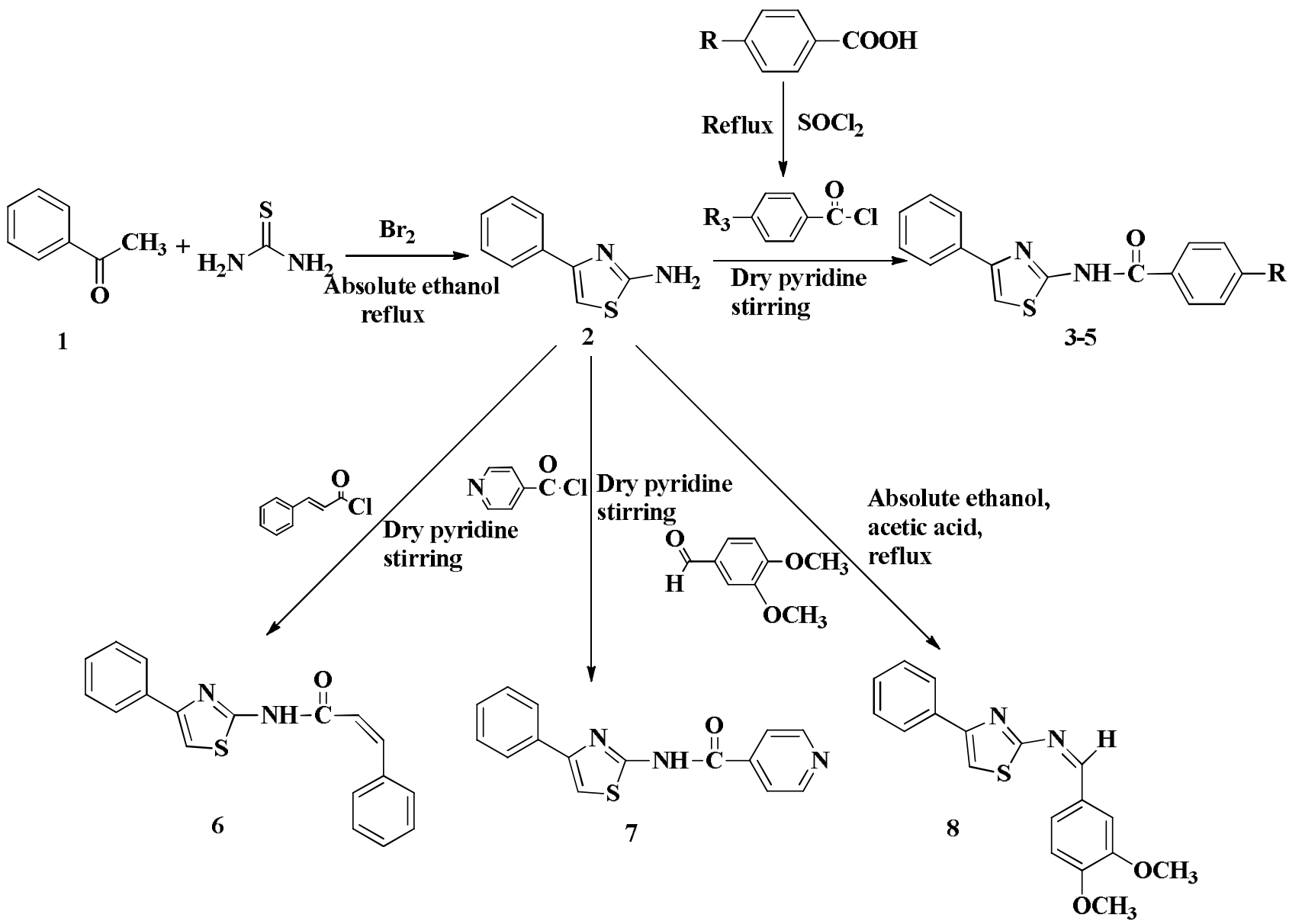

Scheme. 1: Scheme for synthesis of $N$-(4-phenyl-thiazol-2-yl)-benzamide/amide derivatives and (3,4-dimethoxy-benzylidene)-(4-phenyl-thiazol-2-yl)-amine.

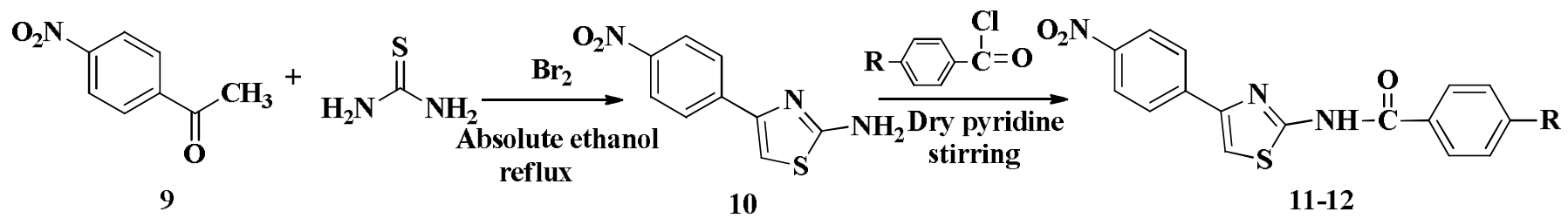

Scheme 2: Scheme for synthesis of 4-(4-nitro-phenyl)-thiazol-2-ylbenzamide derivatives.

\section{Analytical data}

\section{2-Amino-4-phenylthiazole (2)}

Yield (78\%), Mp 138-141 ${ }^{\circ} \mathrm{C}$; IR ( $\mathrm{KBr}$ pellets, $\mathrm{cm}^{-1}$ ): 3435, 3252 ( $\mathrm{NH}$ str., primary amine), 3115 ( $\mathrm{CH}$ str., aromatic), 1599 (C=N str.), 1440 (C=C str., aromatic), 651 (C-S str.); ${ }^{1} \mathrm{H}$ NMR (400 MHz, DMSO- $\left.\mathrm{d}_{6}\right): \delta$ 7.75-7.77 $\left(\mathrm{d}, 2 \mathrm{H}, \mathrm{C}_{2}\right.$ and $\mathrm{C}_{6}$ of phenyl ring), 7.30-7.34 (t, $2 \mathrm{H}, \mathrm{C}_{3}$ and $\mathrm{C}_{5}$ of phenyl ring), 7.20-7.24 $\left(\mathrm{t}, 1 \mathrm{H}, \mathrm{C}_{4}\right.$ of phenyl ring), $6.78\left(\mathrm{~s}, 2 \mathrm{H}, \mathrm{NH}_{2}\right), 6.75(\mathrm{~s}, \mathrm{CH}$ of thiazole nucleus).

\section{N-(4-Phenyl-thiazol-2-yl)-benzamide (3)}

Yield (71\%), Mp 98-101 ${ }^{\circ} \mathrm{C}$; IR ( $\mathrm{KBr}$ pellets, $\mathrm{cm}^{-1}$ ): 3362

(NH str., secondary amide), 3113 (CH str., aromatic), 1676 ( $\mathrm{C}=\mathrm{N}$ str.), 1611 ( $\mathrm{C}=\mathrm{O}$ str., secondary amide), 1442(C=C str., aromatic), 1305 (C-N str.,aromatic) 656 (C-S str.); ${ }^{1} \mathrm{H}$ NMR
(400MHz,DMSO-d $\left.{ }_{6}\right): \delta 12.35(\mathrm{~s}, 1 \mathrm{H}, \mathrm{NH}), 8.16-8.18\left(\mathrm{~d}, 2 \mathrm{H}, \mathrm{C}_{2}\right.$ and $\mathrm{C}_{6}$ of aromatic attach to $\left.\mathrm{C}=\mathrm{O}\right), 7.90-7.92\left(\mathrm{~d}, 2 \mathrm{H}, \mathrm{C}_{2}\right.$ and $\mathrm{C}_{6}$ of phenyl ring attach to thiazole nucleus), 7.56-7.60 (t, $1 \mathrm{H}, \mathrm{C}_{4}$, of aromatic attach to $\mathrm{C}=\mathrm{O}), 7.48-7.52\left(\mathrm{t}, 2 \mathrm{H}, \mathrm{C}_{3}\right.$ and $\mathrm{C}_{5}$ of aromatic ring attach to $\mathrm{C}=\mathrm{O}), 7.38-7.42\left(\mathrm{t}, 2 \mathrm{H}\right.$ of $\mathrm{C}_{2}$ and $\mathrm{C}_{5}$ of phenyl ring attach to thiazole nucleus), 7.34-7.35 (s, 1H, $\mathrm{CH}$ of thiazole nucleus), 7.28-7.32 (t, $1 \mathrm{H}, \mathrm{C}_{4}$ of phenyl nucleus attach to thiazole nucleus).

\section{4-Nitro-N-(4-phenyl-thiazol-2-yl)-benzamide (4)}

Yield (73\%), 169-172 ${ }^{\circ} \mathrm{C}$; IR ( $\mathrm{KBr}$ pellets, $\mathrm{cm}^{-1}$ ): 3357 (NH str., secondary amide), 2923(CH str., aromatic), 1667 (C=O str., secondary amide), $1602 \quad(\mathrm{C}=\mathrm{N} \quad$ str. $), 1550 \quad\left(\mathrm{NO}_{2}\right.$ str. asymmetric), 1470 ( $\mathrm{C}=\mathrm{C}$ str., aromatic), 1344 (C-N str., aromatic), $1327\left(\mathrm{NO}_{2}\right.$ str. symmetric) 654 (C-S str.); ${ }^{1} \mathrm{H}$ NMR $(400 \mathrm{MHz}$, 
DMSO-d $\left.{ }_{6}\right): \delta 12.39(\mathrm{~s}, 1 \mathrm{H}, \mathrm{NH}), 8.57-8.58\left(\mathrm{~d}, 2 \mathrm{H}, \mathrm{C}_{3}\right.$ and $\mathrm{C}_{5}$ of $\mathrm{NO}_{2}$ phenyl), 8.28-8.42 (m, $2 \mathrm{H}, \mathrm{C}_{2}$ and $\mathrm{C}_{6}$ of $\mathrm{NO}_{2}$ phenyl ring), 7.28-7.46 (m, 5H, phenyl ring attached to thiazole), 6.78-6.95 (s, $1 \mathrm{H}, \mathrm{CH}$ of thiazole ring).

\section{4-methoxy-N-(4-phenyl-thiazol-2-yl)-benzamide (5)}

Yield (67.7\%), Mp 163-166 ${ }^{\circ} \mathrm{C}$; IR $\quad(\mathrm{KBr}$
pellets, $\mathrm{cm}^{-1}$ ): 3390 (NH str., secondary amide), 3112 (C-H str., aromatic), $2938\left(\mathrm{CH}\right.$ str. of $\left.\mathrm{OCH}_{3}\right), 1684(\mathrm{C}=\mathrm{O}$ str., secondary amide), 1662 ( $\mathrm{C}=\mathrm{N}$ str.), 1605 ( $\mathrm{C}=\mathrm{C}$ str., aromatic), 1304 (C-N str.), 1256 (C-O-C str. asymmetric), 1129 (C-O-C str. symmetric), 658 (C-S str.); ${ }^{1} \mathrm{H}$ NMR (400 MHz, DMSO-d ${ }_{6}$ ): $\delta$ 8.15-8.18 $\left(\mathrm{d}, 1 \mathrm{H}, \mathrm{C}_{2}\right.$ of phenyl ring attached to thiazole nucleus), 7.90-7.94 (m, 3H, $\mathrm{C}_{3}, \mathrm{C}_{5}$ and $\mathrm{C}_{6}$ of phenyl ring attached to thiazole nucleus), 7.39-7.42 (t, $1 \mathrm{H}, \mathrm{C}_{4}$ of phenyl ring attached to thiazole nucleus), 7.28-7.31 (s, $1 \mathrm{H}, \quad \mathrm{CH}$ of thiazole ring), 6.99-7.01 (d, $2 \mathrm{H}, \mathrm{C}_{2}$ and $\mathrm{C}_{6}$ of methoxy phenyl ring), 6.90-6.93 (d, $2 \mathrm{H}, \mathrm{C}_{3}$ and $\mathrm{C}_{5}$ of methoxy substituted phenyl ring), $4.88(\mathrm{~s}, 1 \mathrm{H}, \mathrm{NH}), 3.84-3.87\left(\mathrm{~s}, 3 \mathrm{H}, \mathrm{OCH}_{3}\right.$ attached to phenyl ring).

\section{3-Phenyl-N-(4-phenylthiazol-2-yl)acrylamide (6)}

Yield (68\%), $174-177^{\circ} \mathrm{C}$; IR ( $\mathrm{KBr}$ pellets, $\left.\mathrm{cm}^{-1}\right): 3428$ (NH str., secondary amide), 3142 (CH str., aromatic), 1675 (C=O str., secondary amide), 1622 ( $\mathrm{C}=\mathrm{N}$ str.), 1557 ( $\mathrm{C}=\mathrm{C}$ str., aromatic), 1493 (C=C str., aromatic), 1334 (C-N str., aromatic), 660 (C-S, str.); ${ }^{1} \mathrm{H}$ NMR (400 MHz, DMSO-d ${ }_{6}$ ): $\delta 12.38$ (s, 1H, NH), 7.877.89 (d, $2 \mathrm{H}, \mathrm{C}_{2}$ and $\mathrm{C}_{6}$ of phenyl ring attached to thiazole), 7.54$7.58\left(\mathrm{~m}, 3 \mathrm{H}, \mathrm{C}_{3}, \mathrm{C}_{4}\right.$ and $\mathrm{C}_{5}$ of phenyl ring attached to thiazole), 7.39-7.47 (m, 5H, phenyl ring of cinnamoyl moiety), 7.37-7.38 (s, $2 \mathrm{H}, \mathrm{CH}$ of $\mathrm{CH}=\mathrm{CH}$ attached with phenyl nucleus), 6.95-6.98 (s, $1 \mathrm{H}, \mathrm{CH}$ of thiazole).

\section{N-(4-phenyl-thiazol-2-yl)-isonicotinamide (7)}

Yield (55.1\%), Mp 188-191 $\quad{ }^{\circ} \mathrm{C}, \quad$ IR $\quad(\mathrm{KBr}$ pellets, $\mathrm{cm}^{-1}$ ): 3433 (NH str., secondary amide), 3057 (CH str., aromatic), 1670 ( $\mathrm{C}=\mathrm{O}$ str., secondary amide), 1554 ( $\mathrm{C}=\mathrm{N}$ str.), 1423 (C=C str., aromatic), 1304 (C-N str., aromatic), 694 (C-S str.); ${ }^{1} \mathrm{H}$ NMR (400 MHz, DMSO-d ${ }_{6}$ ): $\delta 9.192$ (s, 1H, NH), 8.82$8.83\left(\mathrm{~d}, 1 \mathrm{H}, \mathrm{C}_{3}\right.$ of pyridine nucleus $), 8.26-8.28\left(\mathrm{~d}, 1 \mathrm{H}, \mathrm{C}_{4}\right.$ of pyridine nucleus), 7.84-7.86 $\left(\mathrm{d}, 2 \mathrm{H}, \mathrm{C}_{2}\right.$ and $\mathrm{C}_{5}$ of pyridine nucleus), 7.38-7.52 (m, $5 \mathrm{H}$ of phenyl nucleus attached to thiazole nucleus).

\section{(3,4-Dimethoxy-benzylidene)-(4-phenyl-thiazol-2-yl)-amine (8)} Yield (62.2\%), Mp 224-227 ${ }^{\circ} \mathrm{C}$, IR ( $\mathrm{KBr}$ pellets, $\left.\mathrm{cm}^{-1}\right)$ : 2933 (CH str.), 1645 (C=N str.), 1599 (C=C str., aromatic), 1334 (C-N str), 1024 (C-O str.) 1250 (C-O-C str. asymmetric), 1130 (C-O-C str. symmetric) 653 (C-S str.); ${ }^{1} \mathrm{H}$ NMR (400 MHz, DMSO-d $\left.{ }_{6}\right): \delta 8.89(\mathrm{~s}, 1 \mathrm{H}, \mathrm{CH}$ of $\mathrm{CH}=\mathrm{N}), 7.35-$ $7.37\left(\mathrm{~d}, 2 \mathrm{H}, \mathrm{C}_{1}\right.$ and $\mathrm{C}_{6}$ of aromatic ring attached to thiazole nucleus), 7.13-7.26 (t, $3 \mathrm{H}, \mathrm{C}_{3}, \mathrm{C}_{4}, \mathrm{C}_{5}$ of phenyl attached to thiazole nucleus $)$, 6.76-7.05 (m, 3H, aromatic hydrogens of dimethoxy phenyl), 5.80 (s, $1 \mathrm{H}, \mathrm{CH}$ of thiazole), 3.69-3.77 (s, $\left.6 \mathrm{H}, \mathrm{OCH}_{3}\right)$.
4-(4-Nitro-phenyl)-thiazol-2-ylamine (10)

Yield (55.4\%), 221-224 ${ }^{\circ} \mathrm{C}$, IR (KBr pellets, $\left.\mathrm{cm}^{-1}\right): 3398$, 3306 (NH str., primary amine), 3151 (CH str., aromatic), 1639 $\left(\mathrm{C}=\mathrm{N}\right.$ str.), $1593 \quad\left(\mathrm{C}=\mathrm{C} \quad\right.$ str., aromatic), $1539 \quad\left(\mathrm{NO}_{2} \quad\right.$ str., asymmetric), 1348 ( $\mathrm{NO}_{2}$ str., symmetric), 652 (C-S str.); ${ }^{1} \mathrm{H}$ NMR (400 MHz, DMSO-d ${ }_{6}$ ): $\delta 6.82\left(\mathrm{~s}, 2 \mathrm{H}, \mathrm{NH}_{2}\right.$ ), 7.90-7.92 (d, 2H, $\mathrm{C}_{2}$ and $\mathrm{C}_{6}$ of phenyl ring), 8.52-8.57 (t, $2 \mathrm{H}, \mathrm{C}_{3}$ and $\mathrm{C}_{5}$ of phenyl ring), $6.86\left(\mathrm{~s}, 2 \mathrm{H}, \mathrm{NH}_{2}\right), 6.80$ (s, $\mathrm{CH}$ of thiazole nucleus).

\section{N-[4-(4-Nitro-phenyl)-thiazol-2-yl]-benzamide (11)}

Yield (60.9\%), Mp 203-207 ${ }^{\circ} \mathrm{C}$, IR (KBr pellets, $\mathrm{cm}^{-1}$ ): 3400 (NH str., secondary amide), 3149 (CH str., aromatic), 1645 ( $\mathrm{C}=\mathrm{O}$ str., secondary amide), 1593 ( $\mathrm{C}=\mathrm{C}$ str., aromatic), 1558 $\left(\mathrm{C}=\mathrm{N}\right.$ str.), $1539 \quad\left(\mathrm{NO}_{2}\right.$ str. asymmetric), $1345 \quad\left(\mathrm{NO}_{2}\right.$ str., symmetric), 1338 (C-S str., aromatic); ${ }^{1} \mathrm{H}$ NMR (400 MHz, DMSO- $\left.\mathrm{d}_{6}\right): \delta 12.60(\mathrm{~s}, 1 \mathrm{H}, \mathrm{NH}), 8.65-7.80(\mathrm{~m}, 4 \mathrm{H}$, phenyl ring attached to thiazole nucleus), 7.20 (s, $\mathrm{CH}$ of thiazole) 7.02-6.90 (m, 5H, ArH)

\section{4-Methoxy-N-[4-(4-nitro-phenyl)-thiazol-2-yl]-benzamide (12)}

Yield (46.1\%), Mp 198-201 ${ }^{\circ} \mathrm{C}$, IR (KBr pellets, $\mathrm{cm}^{-1}$ ): 3400 (NH str., secondary amide), 3149 (C-H str., aromatic), 2940 $\left(\mathrm{CH}\right.$ str of $\left.\mathrm{OCH}_{3}\right), 1645$ (C=O str., secondary amide), $1593(\mathrm{C}=\mathrm{C}$ str., aromatic), 1558 (C=N str.), 1539 ( $\mathrm{NO}_{2}$ str. asymmetric), 1338 (C-N str., aromatic), 1288 (C-O-C str. asymmetric), 1109 (C-O-C str. symmetric), 643 (C-S str.); ${ }^{1} \mathrm{H}$ NMR (400 MHz, DMSO-d ${ }_{6}$ ): $\delta$ $12.58(\mathrm{~s}, 1 \mathrm{H}, \mathrm{NH}), 8.50-7.75(\mathrm{~m}, 4 \mathrm{H}$, phenyl ring attached to thiazole nucleus), 7.35-7.38 (s, CH of thiazole) $6.80-6.91(\mathrm{~m}, 4 \mathrm{H}$, ArH of methoxy phenyl ring), 3.87-3.90 (t, 3H, $\mathrm{OCH}_{3}$ group attached to phenyl ring).

\section{Antimicrobial evaluation}

The antimicrobial estimation of synthesized compounds was carried out against Gram-positive bacteria: Staphylococcus aureus MTCC 7443, Bacillus subtilis MTCC 441, Gram-negative bacterium: Escherichia coli MTCC 42 and fungal strains: Candida albicans MTCC 183 and Aspergillus niger MTCC 282 by tube dilution method (Cappucino and Sherman, 1999). The standard and test samples were dissolved in DMSO to give a concentration of $100 \mu \mathrm{g} / \mathrm{ml}$. Dilutions of test and standard compounds were prepared in double strength nutrient broth - I.P. (bacteria) or Sabouraud dextrose broth I.P. (fungi) (Indian Pharmacopoeia, 2007). The samples were incubated at $37^{\circ} \mathrm{C}$ for $24 \mathrm{~h}$ (bacteria), at $25{ }^{\circ} \mathrm{C}$ for 7 days $\left(A\right.$. niger) and at $37{ }^{\circ} \mathrm{C}$ for $48 \mathrm{hrs}$ (C. albicans) respectively, and the results were recorded in terms of MIC (the lowest concentration of compound inhibited the growth of microorganisms).

\section{Molecular docking studies}

Molecular docking studies of synthesized compounds were carried out on the target protein glucosamine-6-phosphate synthase (PDB Id: 1jxa) which catalysis the complex reaction involving ammonia transfer from L-glutamine to Fru-6-P, (DutkaMalen et al., 1988; Bates et al., 1966) followed by isomerisation 
of the formed fructosamine-6-phosphate to glucosamine-6phosphate. The ligands were drawn in ChemBioDraw Ultra 12.0 followed by MM2 minimization of ligands (using ChemBio3D Ultra 12.0) by keeping a check on the connection error in the bonds. Protein and Grid preparation was done using Autodock Vina 1.1.2 (Trott et al., 2010) and was used to perform molecular docking.

\section{QSAR studies}

The QSAR study was performed to correlate antimicrobial activity with physicochemical parameters of synthesized thiazole derivatives. The structures of synthesized thiazole derivatives were first pre-optimized with the Molecular Mechanics Force Field method $\left(\mathrm{MM}^{+}\right)$included in Hyperchem 6.03 (1993) and the resulting geometries were further refined by means of the semiempirical method PM3 (parametric method-3). Gradient norm limit of $0.01 \mathrm{kcal} / \mathrm{A}^{\circ}$ was utilized for the geometry optimization. TSAR 3.3 software for Windows (TSAR 3D Version $3.3,2000)$ was used to calculate physicochemical parameters of lowest energy structures of synthesized thiazole derivatives. Further, the regression analysis was carried out using the SPSS software package (SPSS for Windows, 1999). The predictive powers of the developed models were supported by cross-validated $\mathrm{r}^{2}\left(\mathrm{q}^{2}\right)$ using leave one out (LOO) cross-validation method (Schaper, 1999). The statistical qualities of equations were further confirmed by the parameters like standard error of estimate (s), correlation coefficient (r), variance ratio $(\mathrm{F})$ at specified degrees of freedom, root mean square error (RMSE) and predicted error sum of square (PRESS).

\section{RESULTS AND DISCUSSION}

\section{Chemistry}

The synthesis of the intermediate ( 2 and 10) and target compounds (3-8 and 11-12) were performed according to the reactions outlined in Scheme 1 and 2. Acid chloride was synthesized by refluxing acid with distilled thionyl chloride. Then, corresponding acid chlorides and synthesized thiazole derivatives were stirred at $0-10{ }^{\circ} \mathrm{C}$ in dry pyridine to yield the target $\mathrm{N}$-(4phenyl-thiazol-2-yl)-benzamide/amide derivatives (3-7 and 11-12). On the other hand, compound $N$-(3,4-dimethoxybenzylidene)-4phenylthiazol-2-amine (8) was synthesized by condensation of intermediate (2) with veratraldehyde in presence of acetic acid. In this study we obtained some thiazole derivatives in good yield and some in moderate to low yield. The physicochemical properties of synthesized compounds are presented in Table 1.

Chemical structures of synthesized compounds (2-8 and 10-12) were ascertained on the basis of their ${ }^{1} \mathrm{H}$ NMR and IR spectral data. The appearance of singlet signal ranging from $\delta 6.75$ to $7.38 \mathrm{ppm}$ in the synthesized compounds confirmed the presence of $\mathrm{CH}$ of thiazole ring (compounds 2-8). The presence of singlet signal of NH proton in compounds (3-6 and 10-12) in the range of $\delta$ 12.35-12.68 ppm revealed the formation of amide bond in the synthesized derivatives. The presence of aromatic protons in synthesized derivatives was confirmed by the multiplet signal in the range of $\delta 7.01$ to $\delta 8.65 \mathrm{ppm}$. The presence of methoxy group in compounds $\mathbf{5}, \mathbf{8}$ and $\mathbf{1 2}$ was confirmed by singlet peak present in the region of $\delta 3.69-3.90 \mathrm{ppm}$. Moreover, the absence of singlet peak of $\mathrm{NH}_{2}$ protons at $\delta 6.78 \mathrm{ppm}$ in target compounds (3-8 and 11-12) and presence of same peak in intermediate (2) confirmed their synthesis.

The presence of the $\mathrm{C}=\mathrm{O}$ functional group (compounds 3-7, 11-12) was indicated by the appearance of a stretching band around $1675 \mathrm{~cm}^{-1}$, which is the characteristic of an amide linkage. The presence of the $\mathrm{C}=\mathrm{C}$ str. (aromatic) was indicated by the appearance of a stretching band around 1450-1600 $\mathrm{cm}^{-1}$ in compounds 2-12. The appearance of IR band around 3100-3400 $\mathrm{cm}^{-1}$ showed the presence of $\mathrm{NH}$ linkage of amide bond in synthesized derivatives. The appearance of $\mathrm{C}-\mathrm{S}$ band around 650 $\mathrm{cm}^{-1}$ in compounds $\mathbf{2 - 1 2}$ indicated the presence of thiazole nucleus. In compounds $\mathbf{5 , 8}$ and $\mathbf{1 2}$ stretching band around 2940 $\mathrm{cm}^{-1}$ revealed the presence of methoxy group. Further, the aromatic nitro stretching around $1550 \mathrm{~cm}^{-1}$ (asymmetric $\mathrm{NO}_{2}$ stretching) and $1350 \mathrm{~cm}^{-1}$ (symmetric $\mathrm{NO}_{2}$ str.) depicted the presence of nitro functional group in synthesized compounds 4,11 and 12. The presence of $\mathrm{C}-\mathrm{N}$ bond in synthesized compounds was indicated by stretching band around $1334 \mathrm{~cm}^{-1}$. In compounds $\mathbf{5 , 8}$ and 12 stretching at around $1130 \mathrm{~cm}^{-1}$ (symmetric $\mathrm{C}-\mathrm{O}-\mathrm{C}$ stretching) and $1250 \mathrm{~cm}^{-1}$ (asymmetric $\mathrm{C}-\mathrm{O}-\mathrm{C}$ stretching) revealed the presence of methoxy group.

\section{Antimicrobial activity}

The synthesized thiazole derivatives (2-12) were evaluated for their in vitro antibacterial activity against Grampositive S. aureus, B subtilis and Gram-negative $E$ coli and antifungal activity against $C$. albicans and $A$. niger by tube dilution method (Cappucino and Sherman, 1999). Double strength Nutrient broth I.P. and Sabouraud dextrose broth I.P. have been employed as media for growth of bacterial and fungal cells, respectively (Indian Pharmacopoeia, 2007).

The pMIC values of antimicrobial activity $\left(\mu \mathrm{M} \mathrm{ml}^{-1}\right)$ are presented in Table 2. In case of B. subtilis, compounds 4, 8, 11 and 12 were found to be more active than the other synthesized derivatives with $\mathrm{pMIC}_{\mathrm{bs}}$ value range 3.92-4.01 $\mu \mathrm{M} \mathrm{ml}^{-1}$. Against $S$. aureus, compounds $\mathbf{4 , 8}$ and 12 were found to be most active than the other synthesized derivatives $\left(\mathrm{pMIC}_{\mathrm{sa}}\right.$ range $=4.51-4.60 \mu \mathrm{M}$ $\mathrm{ml}^{-1}$ ). Again compounds 4, 8 and 12 were found to be most potent against the Gram-negative bacteria, E. coli having $\mathrm{pMIC}_{\mathrm{ec}}$ value 4.51-4.60 $\mu \mathrm{M} \mathrm{ml}^{-1}$ among synthesized derivatives.

On the other hand, results of antifungal activity revealed that the compounds $4,8,11$ and 12 were able to produce good inhibitory activity against $C$. albicans $\left(\mathrm{pMIC}_{\mathrm{ca}}=3.92-4.01 \mu \mathrm{M} \mathrm{ml}^{-}\right.$ $\left.{ }^{1}\right)$. For antifungal activity against $A$. niger compounds $\mathbf{1 1}$ and $\mathbf{1 2}$ showed more potent activity having $\mathrm{pMIC}_{\mathrm{an}}$ value 4.01-4.23 $\mu \mathrm{M}$ $\mathrm{ml}^{-1}$ than other synthesized derivatives. Results of antimicrobial (antibacterial and antifungal) activities showed that compounds having phenyl substituted $p$-methoxy and $p$-nitro moities were the most potent ones $\left(\mathrm{pMIC}\right.$ range $=3.79-4.60 \mu \mathrm{M} \mathrm{ml}^{-1}$ ) as compared 
to other synthesized derivatives. Moreover, compounds with $p$ nitro phenyl moiety (11 and 12) attached at $4^{\text {th }}$ position of thiazole ring were the most potent ones against tested antifungal strains (pMIC $\left.=3.93-4.23 \mu \mathrm{M} \mathrm{ml}^{-1}\right)$. Further, it is observed that compound 12 having $p$-methoxy and $p$-nitro substituted phenyl ring showed most potent antimicrobial activity $(\mathrm{pMIC}=4.60)$ among synthesized derivatives against $S$. aureus and E. coli.

\section{Structure activity relationship on the basis of antimicrobial activity results}

1. The replacement of hydrogen of $\mathrm{NH}_{2}$ group (2 and 10) with benzamide (3-5 and 11-12), amide (6-7) and 3,4dimethoxybenzylidene (8) led to a noticeable increase in antimicrobial activity of the synthesized compounds against $S$. aureus and $E$. coli. This may be due to the increase in lipophilicity of synthesized derivatives, which may allow them to easily penetrate the microbial membrane (Fig. 1).

2. The higher antimicrobial activity of compounds $\mathbf{4}, \mathbf{1 1}$ and $\mathbf{1 2}$ may be due to the presence of electron withdrawing $\mathrm{NO}_{2}$ group at para position of phenyl ring. Role of electron withdrawing group in improving antimicrobial activity is in accordance with the finding of Sharma et al. (2004).

3. Synthesized derivatives demonstrated low antibacterial and antifungal activity compared to reference drugs Ciprofloxacin and Fluconazole respectively, against all tested microbial species.

4. The presence of electron donating $\mathrm{OCH}_{3}$ group $(\mathbf{5}, \mathbf{8}$ and 12) conferred higher antibacterial activity to the synthesized thiazole derivatives, specifically against $S$. aureus and E.coli (pMIC range $=4.49-4.60)$.

5. Compound (6) synthesized from cinnamic acid, has displayed better activity as compared to unsubstituted derivative (2). This may be due to the presence of extended conjugation in cinnamic acid, which may be involved in binding of synthesized compound with target site. This fact is supported by study of Narasimhan et al. (2007).

6. The aforementioned results indicated the fact that different structural requirements are essential for a compound to be selected as antibacterial or antifungal agent. This is similar to the results obtained by Sortino et al. (2007).

\section{Molecular docking studies}

Molecular docking studies were carried out to understand the binding profile of synthesized thiazole derivatives and to support the in vitro antimicrobial activity data. Automated docking was used to determine the orientation of inhibitors bound in the active site of bacterial glucosamine-6-phosphate synthase (PDB ID 1jxa) (Sarojini et al., 2010). A Lamarckian genetic algorithm method, implemented in the program AutoDock Vina 1.1.2, was employed. The 3D-structure of bacterial glucosamine-6-phosphate synthase is presented in Fig. 2.

The docking of series of ligands (2-12) with glucosamine-6-phosphate synthase (GlcN-6-P synthase) indicated that all the synthesized compounds have potential of binding with one or the other amino acids in the active pockets as evident from the docking scores provided in Table 3. The 2D structure of ligand was drawn on ChemBioDrawUltra 12.0. and 3D coordinates were developed using ChemBio3D ultra 12.0 after performing MM2 minimization.

The protein structure file (PDB ID: 1jxa) taken from RCSB Protein Data Bank (PDB) was prepared for docking by removal of water molecules, adding polar hydrogens and Kollman charges to the structure file. In silico prediction of amino acids involved in the active site of protein responsible for binding with the ligands are obtained from the co-crystallized endogenous ligand from the PDB file. Ligand preparation is done by adding Gasteiger charges. Different conformations of ligands were built by allowing rotation of all torsions during docking.

Theoretically all the synthesized compounds showed very good binding scores ranging from -5.4 to $-9.1 \mathrm{kcal} / \mathrm{mol}$. Out of the ten compounds nine have shown docking scores much better than the docking score of co-crystallized ligand $(-5.9 \mathrm{kcal} / \mathrm{mol})$. Molecular docking studies revealed that compounds $\mathbf{1 1}$ and $\mathbf{1 2}$ is showing excellent binding score of more than $-9.0 \mathrm{kcal} / \mathrm{mol}$ as the nitro group at para position in these compounds is making hydrogen bonding interaction with $\operatorname{Arg} 383$ and $\operatorname{Arg} 173$ (in 11) and with Glu396 and Gln346 (in 12) (Figure 3).

These compounds are also showing strong hydrophobic interaction with Pro177. In case of compound 12, an extra $\pi$ stacking interaction which is generally known as sandwich type $\pi$ stacking interaction is being shown by Phe205 and Pro177 through the phenyl moiety carrying methoxy group. It can be justified as result of electron releasing effect of methoxy group which might increased the electron density of the $\pi$-cloud of the aromatic ring of the ligand and helps in providing sufficient stabilization.

Thus, hydrophobic interactions also tend to stabilize the binding site and thus should be considered as important parameter for drug design. The stabilization of receptor-ligand binding state through hydrophobic interactions is also reported by Singh et al. (2014) for biguanide based compounds for quorum sensing activity. The present data supports the in vitro results which suggest that compounds $\mathbf{1 1}$ and $\mathbf{1 2}$ are showing high antimicrobial activity against all the tested microorganisms. Hence, it can be predicted that activity may be due to inhibition of enzyme GlcN-6$\mathrm{P}$ synthase, which catalyses a reaction which involves transfer of amine group from L-glutamine to Fru-6-P, followed by isomerisation of the fructosamine-6-phosphate to glucosamine-6phosphate.

\section{QSAR studies}

\section{Development of one-target QSAR models (ot-QSAR)}

Quantitative structure activity relationship (QSAR) is one of the most influential method for the prediction of biological 
activity of compounds. QSAR technique also important in finding quantitative relationships between the molecular structure and biological activity of investigated compounds (Mohsen et al., 2010). In the present study, we have performed the QSAR studies by Hansch's analysis using the linear free energy relationship (LFER) model described by Hansch and Fujita (1964).

In Hansch's approach, structural properties of compounds are calculated in terms of different physicochemical parameters and these parameters are correlated with biological activity through equation using regression analysis. Before using the biological activity data for QSAR study experimentally determined MIC values changed to $-\log$ MIC or pMIC (in micromole) to get all the values positive, normal distribution of errors and to get linear free energy relationship of these data with physicochemical parameters. Further, regression analysis was performed using calculated physicochemical parameters (Table 4 and 5) as independent variables and antimicrobial activity values as dependent variables (Table 2).

On the basis of intercorrelation between the independent variables and also their individual correlation with antimicrobial activity, different probable combinations of parameters were subjected to linear regression (LR) and multiple linear regression (MLR) analysis. Out of hundreds of equations generated, some of the best QSAR equations having significant statistical values are selected.

These equations were generated in stepwise manner by forward selection method starting with best single variable and adding further significant variable according to their contribution to the model that leads to the smallest standard deviation (s), until there is no other variable outside the equation that satisfies the selection criteria.

The different physicochemical parameters viz. topological, electronic, thermodynamic, and spatial (Hansch and Fujita, 1964; Hansch et al., 1973; Kier and Hall, 1976; Randic 1975; Balaban 1982; Wiener, 1947; Randic, 1993) were quantified using TSAR 3.3 software (TSAR 3D for Windows, Version 3.3, 2000) for synthesized thiazole derivatives are summarized in Table 4 and the values of selected parameters are presented in Table 5.

In view of above facts, a data set of 10 synthesized thiazole derivatives was used for model development. The predictive powers of derived QSAR models were confirmed by leave one out (LOO) method (Schaper, 1999), where a model is built with $\mathrm{N}$ - 1 compounds and $\mathrm{N}^{\text {th }}$ compound is predicted. Each compound is eliminated for model derivation and predicted in turn. The same procedure is repeated after elimination of another compound until all the compounds have been eliminated once.

A correlation matrix constructed for antibacterial activity against $S$. aureus is presented in Table 6. Both high and low colinearity was observed between different physicochemical properties. A highest interrelationship was observed between ${ }^{1} \chi^{\mathrm{v}}$ and MR ( $\mathrm{r}=0.997)$ and lowest interrelationship was observed between ${ }^{3} \chi$ and $\log \mathrm{P}(\mathrm{r}=0.376)$. The correlations of different parameters with antimicrobial activities are presented in Table 7.
A significant correlation ( $\mathrm{r}>0.7$ ) was observed against all tested microbial strains with most of selected parameters except ${ }^{3} \chi$ (Table 7).

$$
\begin{aligned}
& \text { ot-QSAR model for antibacterial activity against } S \text {. aureus } \\
& \mathrm{pMIC}_{\mathrm{sa}}=0.462( \pm 0.054)^{2} \chi^{\mathrm{v}}+1.834( \pm 0.278) \text { eq. } 1 \\
& \mathrm{n}=10 \quad \mathrm{r}=0.950 \mathrm{r}^{2}=0.902 \\
& \mathrm{q}^{2}=0.891 \quad \mathrm{~s}=0.135 \mathrm{~F}=74.361 \\
& \mathrm{pMIC}_{\mathrm{sa}}=1.039( \pm 0.195)^{2} \chi^{\mathrm{v}}-0.468( \pm 0.156) \kappa_{3}+0.852( \pm 0.381) \text { eq. } 2 \\
& \mathrm{n}=10 \quad \mathrm{r}=0.979 \mathrm{r}^{2}=0.958 \\
& \mathrm{q}^{2}=0.946 \quad \mathrm{~s}=0.096 \mathrm{~F}=79.084 \\
& \mathrm{PRESS}=0.064 \quad \mathrm{RMSE}=0.253
\end{aligned}
$$

The developed QSAR equation (Eq. 1) showed that the valence second order connectivity index $\left({ }^{2} \chi^{v}\right)$ is favorable for antibacterial activity against $S$. aureus. The coefficient of ${ }^{2} \chi^{v}$ is positive which indicated that activity against $S$. aureus increases with increase in ${ }^{2} \chi^{v}$ value of synthesized thiazole derivatives. This is clearly evident from Table 5, that compounds (4, 8 and 12) having high ${ }^{2} \chi^{v}$ values, 5.59, 5.66 and 5.95 have high antibacterial activity values (Table 2), 4.51, 4.51 and 4.60, respectively. Similarly, compounds (2 and 10) with low ${ }^{2} \chi^{\mathrm{v}}$ values (3.40 and 3.84) have low antibacterial activity $\left(\mathrm{pMIC}_{\mathrm{sa}}=3.39\right.$ and 3.59 , respectively) against $S$. aureus (Table 2).

Although there is high interrelationship ( $\mathrm{r}=0.950$, Eq. 1) between ${ }^{2} \chi^{v}$ and other parameters, still we go for the development of biparametric models to get better regression coefficient. The maximum increase in $r$ value was observed on combination of ${ }^{2} \chi^{v}$ and Kier's shape topological index $\left(\kappa_{3}\right)(r=0.979$, Eq. 2). High $r$ (0.979) and $\mathrm{q}^{2}(0.946)$ values revealed the significance of ${ }^{2} \chi^{\mathrm{v}}$ and $\kappa_{3}$ (Eq. 2) in describing antibacterial activity against $S$. aureus of synthesized thiazole derivatives.

The values of $r$ and $\mathrm{q}^{2}$ for Eq. 2 are 0.979 and 0.946, which means that the resulted QSAR model could explain and predict $97.9 \%$ and $94.6 \%$ of variances, respectively. Generally, when $\mathrm{q}^{2}$ are larger than 0.5 , the model are considered to have sound predictive power. However, several studies recommended that a high $\mathrm{q}^{2}$ appear to be a necessary, but not sufficient, condition for a model to have a highly accurate predictive power (Oltulu et al., 2009). Consequently, various other statistical approaches were used to validate the robustness and the practical applicability of the developed QSAR models.

To demonstrate that the resulted equations have good prediction of antimicrobial activity of selected thiazole derivatives, some different methods of evaluation of model performance have been used. Here, $r^{2}$, which presents the explained variance for given set, was used to determine the goodness of model's fit performance. Low values of RMSE and PRESS further confirmed the validity of developed QSAR models. Moreover, low residual values indicated that experimental and predicted antimicrobial activities are very close to each other also confirmed the robustness of developed models (Table 8). 
Fig. 1: Structural requirements for antimicrobial activity of synthesized 2,4-disubstituted thiazole derivatives.

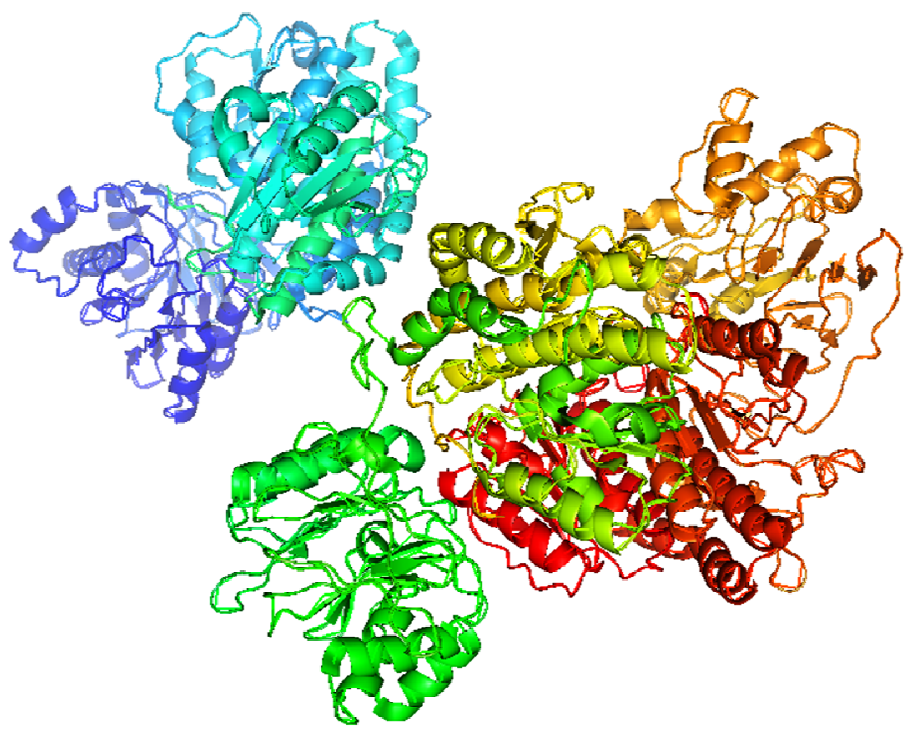

Fig. 2: Structure of bacterial glucosamine-6-phosphate synthase (PDB ID 1jxa).

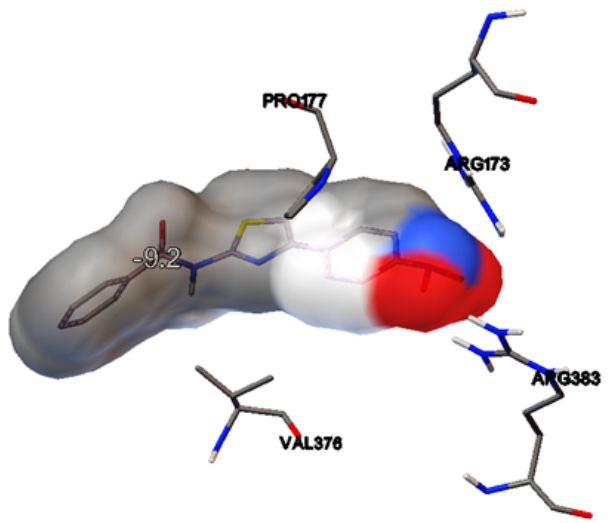

11

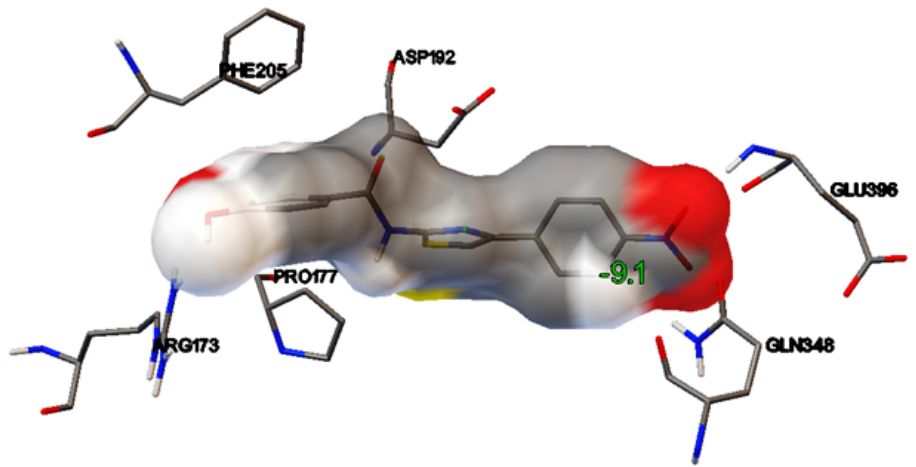

12

Fig. 3: The binding of ligands (11 and 12) on A chain amino acids present in an active site of GlcN-6-P with hydrogen bonds and hydrophobic interactions.

Table 1: Physicochemical properties of the synthesized thiazole derivatives

\begin{tabular}{|c|c|c|c|c|c|c|}
\hline Compounds & Mol. Formula & Mol. Wt. & $\mathrm{Mp}\left({ }^{\circ} \mathrm{C}\right)$ & $\mathrm{R}_{\mathrm{f}}$ & $\%$ yield & $\mathrm{R}$ \\
\hline 2 & $\mathrm{C}_{9} \mathrm{H}_{8} \mathrm{~N}_{2} \mathrm{~S}$ & 176 & $138-141$ & $0.89^{\mathrm{a}}$ & 78.2 & - \\
\hline 3 & $\mathrm{C}_{16} \mathrm{H}_{12} \mathrm{~N}_{2} \mathrm{OS}$ & 280 & $98-101$ & $0.85^{\mathrm{c}}$ & 71.5 & $\mathrm{H}$ \\
\hline 4 & $\mathrm{C}_{16} \mathrm{H}_{11} \mathrm{~N}_{3} \mathrm{O}_{3} \mathrm{~S}$ & 325 & $169-172$ & $0.77^{\mathrm{d}}$ & 73.2 & $\mathrm{NO}_{2}$ \\
\hline 5 & $\mathrm{C}_{17} \mathrm{H}_{14} \mathrm{~N}_{2} \mathrm{O}_{2} \mathrm{~S}$ & 310 & $163-166$ & $0.58^{\mathrm{d}}$ & 67.7 & $\mathrm{OCH}_{3}$ \\
\hline 6 & $\mathrm{C}_{18} \mathrm{H}_{14} \mathrm{~N}_{2} \mathrm{OS}$ & 306 & $174-177$ & $0.78^{\mathrm{d}}$ & 68.6 & $\mathrm{H}$ \\
\hline 7 & $\mathrm{C}_{15} \mathrm{H}_{11} \mathrm{~N}_{3} \mathrm{OS}$ & 281 & $188-191$ & $0.55^{\mathrm{a}}$ & 55.1 & - \\
\hline 8 & $\mathrm{C}_{18} \mathrm{H}_{16} \mathrm{O}_{2} \mathrm{~N}_{2} \mathrm{~S}$ & 324 & $224-227$ & $0.65^{\mathrm{b}}$ & 62.2 & - \\
\hline 10 & $\mathrm{C}_{9} \mathrm{H}_{7} \mathrm{O}_{2} \mathrm{~N}_{3} \mathrm{~S}$ & 221 & $221-224$ & $0.54^{\mathrm{a}}$ & 55.4 & - \\
\hline 11 & $\mathrm{C}_{16} \mathrm{H}_{11} \mathrm{O}_{3} \mathrm{~N}_{3} \mathrm{~S}$ & 325 & 203-206 & $0.73^{\mathrm{a}}$ & 60.9 & $\mathrm{H}$ \\
\hline 12 & $\mathrm{C}_{17} \mathrm{H}_{13} \mathrm{O}_{4} \mathrm{~N}_{3} \mathrm{~S}$ & 355 & $198-201$ & $0.73^{\mathrm{a}}$ & 46.1 & $\mathrm{OCH}_{3}$ \\
\hline
\end{tabular}

TLC mobile phase $-{ }^{\mathrm{a}}$ Hexane : Ethyl acetate $(1: 2) ;{ }^{b}$ Pet. Ether : Ethyl acetate $(7: 1) ;{ }^{\mathrm{c}}$ Hexane : Ethyl acetate $(1: 4) ;{ }^{\mathrm{d}}$ Hexane : Ethyl acetate $(2: 1)$ 
Table 2: pMIC values of synthesized 2,4-disubstituted thiazole derivatives

\begin{tabular}{|c|c|c|c|c|c|c|c|c|}
\hline \multicolumn{9}{|c|}{ Minimum inhibitory concentration $\left(\mu \mathrm{M} \mathrm{ml^{-1 } )}\right.$} \\
\hline Comp. & $\mathbf{p M I C}_{\mathrm{bs}}$ & pMIC $_{\mathrm{sa}}$ & pMIC $_{\mathrm{ec}}$ & pMIC $_{\text {ca }}$ & pMIC $_{\text {an }}$ & pMIC $_{\mathrm{ab}}$ & pMIC $_{\text {af }}$ & pMIC $_{\text {am }}$ \\
\hline 2 & 3.39 & 3.39 & 3.39 & 3.39 & 3.39 & 3.39 & 3.39 & 3.39 \\
\hline 3 & 3.79 & 4.41 & 4.41 & 3.79 & 3.79 & 4.20 & 3.79 & 4.04 \\
\hline 4 & 3.93 & 4.51 & 4.51 & 3.93 & 3.93 & 4.32 & 3.93 & 4.16 \\
\hline 5 & 3.89 & 4.49 & 4.49 & 3.89 & 3.89 & 4.29 & 3.89 & 4.13 \\
\hline 6 & 3.87 & 4.18 & 4.18 & 3.57 & 3.87 & 4.08 & 3.72 & 3.94 \\
\hline 7 & 3.20 & 4.11 & 4.11 & 3.81 & 3.81 & 3.80 & 3.81 & 3.80 \\
\hline 8 & 3.92 & 4.51 & 4.51 & 3.92 & 3.92 & 4.31 & 3.92 & 4.16 \\
\hline 10 & 3.59 & 3.59 & 3.59 & 3.29 & 3.59 & 3.59 & 3.44 & 3.53 \\
\hline 11 & 3.93 & 4.23 & 4.23 & 3.93 & 4.23 & 4.13 & 4.08 & 4.11 \\
\hline 12 & 4.01 & 4.60 & 4.60 & 4.01 & 4.01 & 4.40 & 4.01 & 4.24 \\
\hline S.D. & 0.27 & 0.41 & 0.41 & 0.25 & 0.23 & 0.34 & 0.23 & 0.29 \\
\hline Std.* & $2.61^{\mathrm{a}}$ & $2.61^{\mathrm{a}}$ & $2.61^{\mathrm{a}}$ & $2.64^{b}$ & $2.64^{b}$ & 2.61 & 2.64 & 2.62 \\
\hline
\end{tabular}

S.D. Standard deviation $\quad{ }^{\mathrm{a}}$ Ciprofloxacin

Table 3: Docking score of synthesized thiazole derivatives against A chain amino acid present in active site of glucosamine-6-phosphate synthase.

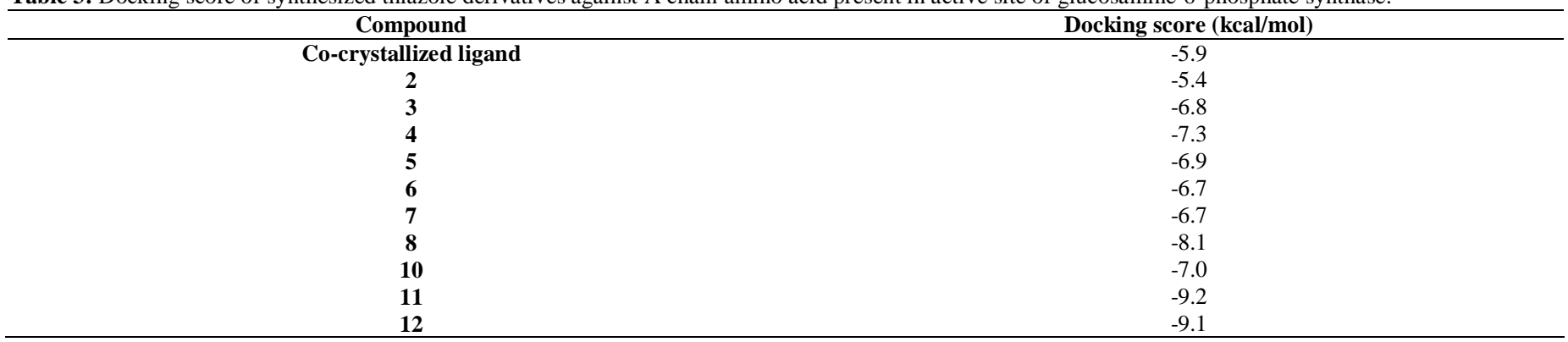

Table 4: Brief description of some molecular descriptors used in the present study

\begin{tabular}{|c|c|c|}
\hline S. No. & Descriptor type & Molecular Description \\
\hline 1 & Topological & 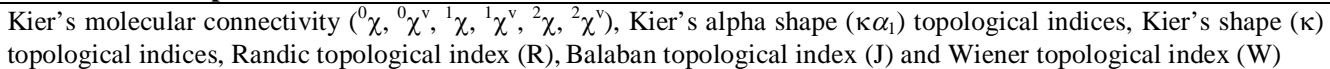 \\
\hline 2 & Quantum & $\begin{array}{l}\text { Total energy (Te), Ionization potential (I.P.), energies of highest occupied molecular orbital (HOMO) and lowest } \\
\text { unoccupied molecular orbital (LUMO), dipole moment }(\mu) \text { and electronic energy (Ele.E) }\end{array}$ \\
\hline 3 & Lipophilic & Log P (Octanol-water partition coefficient) \\
\hline 4 & Spatial & Molecular surface area, Molar volume (Vm) \\
\hline 5 & Structural & Molecular Weight (MW) \\
\hline
\end{tabular}

Table 5: Value of selected descriptors used in the regression analysis

\begin{tabular}{|c|c|c|c|c|c|c|c|c|c|c|c|c|}
\hline Comp. & $\log P$ & ${ }^{0} \chi$ & ${ }^{1} \chi$ & ${ }^{2} \chi$ & ${ }^{2} \chi^{v}$ & ${ }^{3} \chi$ & ${ }^{3} \chi^{v}$ & $\kappa^{3}$ & $\boldsymbol{\kappa} \boldsymbol{\alpha}_{2}$ & $\kappa \boldsymbol{\alpha}_{3}$ & $\mathbf{R}$ & B \\
\hline 2 & 2.48 & 8.39 & 5.86 & 5.08 & 3.40 & 0.62 & 0.31 & 2.04 & 3.38 & 1.76 & 9.25 & 1.92 \\
\hline 3 & 4.03 & 13.79 & 9.83 & 8.45 & 5.15 & 0.94 & 0.43 & 4.02 & 6.12 & 3.23 & 14.81 & 1.57 \\
\hline 4 & 3.98 & 16.23 & 11.13 & 9.97 & 5.59 & 1.44 & 0.54 & 4.76 & 6.91 & 3.76 & 15.72 & 1.59 \\
\hline 5 & 3.78 & 15.36 & 10.76 & 9.24 & 5.51 & 1.14 & 0.49 & 4.52 & 6.97 & 3.70 & 16.49 & 1.59 \\
\hline 6 & 4.44 & 15.20 & 10.81 & 9.26 & 5.56 & 1.03 & 0.45 & 5.26 & 7.30 & 4.24 & 16.63 & 1.56 \\
\hline 7 & 3.18 & 13.79 & 9.83 & 8.45 & 5.02 & 0.94 & 0.43 & 4.02 & 6.34 & 3.37 & 14.38 & 1.56 \\
\hline 8 & 4.54 & 16.07 & 11.30 & 9.43 & 5.66 & 1.07 & 0.49 & 4.76 & 7.92 & 4.11 & 17.75 & 1.60 \\
\hline 10 & 2.44 & 10.84 & 7.16 & 6.60 & 3.84 & 1.12 & 0.43 & 2.77 & 4.18 & 2.28 & 10.16 & 1.97 \\
\hline 11 & 3.98 & 16.23 & 11.13 & 9.97 & 5.59 & 1.44 & 0.54 & 4.76 & 6.91 & 3.76 & 15.72 & 1.59 \\
\hline 12 & 3.73 & 17.81 & 12.06 & 10.76 & 5.95 & 1.64 & 0.61 & 5.26 & 7.76 & 4.24 & 17.40 & 1.60 \\
\hline
\end{tabular}

Table 6: Correlation matrix for antimicrobial activity of synthesized thiazole derivatives against $S$. aureus.

\begin{tabular}{|c|c|c|c|c|c|c|c|c|c|c|c|c|c|}
\hline & $\log P$ & MR & $\chi^{0}$ & ${ }^{0} \chi^{v}$ & ${ }^{1} \chi$ & ${ }^{1} \chi^{v}$ & ${ }^{2} \chi$ & ${ }^{2} \chi^{v}$ & ${ }^{3} \chi$ & ${ }^{3} \chi^{v}$ & $\kappa_{3}$ & $\mathrm{Ka}_{3}$ & SA \\
\hline $\log P$ & 1 & & & & & & & & & & & & \\
\hline MR & 0.906 & 1 & & & & & & & & & & & \\
\hline$\chi_{0}$ & 0.808 & 0.973 & 1 & & & & & & & & & & \\
\hline${ }^{0} \chi^{\mathrm{v}}$ & 0.873 & 0.995 & 0.980 & 1 & & & & & & & & & \\
\hline${ }^{\tilde{n}} \gamma$ & 0.852 & 0.990 & 0.993 & 0.992 & 1 & & & & & & & & \\
\hline${ }^{1} \chi^{\mathrm{v}}$ & 0.897 & 0.997 & 0.969 & 0.992 & 0.991 & 1 & & & & & & & \\
\hline${ }^{2} \chi$ & 0.794 & 0.964 & 0.997 & 0.968 & 0.989 & 0.963 & 1 & & & & & & \\
\hline${ }^{2} \chi^{v}$ & 0.876 & 0.994 & 0.984 & 0.991 & 0.997 & 0.997 & 0.981 & 1 & & & & & \\
\hline${ }^{3} \chi$ & 0.376 & 0.645 & 0.796 & 0.671 & 0.721 & 0.626 & 0.809 & 0.684 & 1 & & & & \\
\hline${ }^{3} \chi^{v}$ & 0.557 & 0.808 & 0.917 & 0.837 & 0.865 & 0.795 & 0.919 & 0.836 & 0.963 & 1 & & & \\
\hline$\kappa_{3}$ & 0.874 & 0.984 & 0.966 & 0.968 & 0.978 & 0.978 & 0.965 & 0.981 & 0.681 & 0.815 & 1 & & \\
\hline$\kappa \boldsymbol{\alpha}_{3}$ & 0.884 & 0.990 & 0.959 & 0.979 & 0.976 & 0.982 & 0.950 & 0.978 & 0.634 & 0.789 & 0.992 & 1 & \\
\hline SA & 0.832 & 0.937 & 0.930 & 0.950 & 0.945 & 0.948 & 0.921 & 0.950 & 0.630 & 0.797 & 0.887 & 0.890 & 1 \\
\hline
\end{tabular}


ot-QSAR model for antibacterial activity against $E$. coli

$\mathrm{pMIC}_{\mathrm{ec}}=0.462( \pm 0.054)^{2} \chi^{\mathrm{v}}+1.834( \pm 0.278)$ eq. 3

$\mathrm{n}=10 \quad \mathrm{r}=0.950 \mathrm{r}^{2}=0.903 \quad \mathrm{q}^{2}=0.891$

$\mathrm{s}=0.135 \quad \mathrm{~F}=74.361$

$\mathrm{pMIC}_{\mathrm{ec}}=1.039( \pm 0.195)^{2} \chi^{\mathrm{v}}-0.468( \pm 0.156) \kappa_{3}+0.852( \pm 0.381)$ eq. 4

$\mathrm{n}=10 \quad \mathrm{r}=0.979 \mathrm{r}^{2}=0.958$

$\mathrm{q}^{2}=0.946 \quad \mathrm{~s}=0.096 \mathrm{~F}=79.084$

PRESS $=0.064 \quad$ RMSE $=0.253$

QSAR analysis of $E$. coli once again revealed the significance of ${ }^{2} \chi^{\mathrm{v}}$ and $\kappa_{3}$ in demonstrating antimicrobial activity. Further, developed QSAR model indicated that antimicrobial activity is positively correlated with ${ }^{2} \chi^{\mathrm{v}}$ and negatively correlated with $\kappa_{3}$ (Eq. 3 and Eq. 4).

$$
\begin{aligned}
& \text { ot-QSAR model for antibacterial activity against } B \text {. subtilis } \\
& \mathrm{pMIC}_{\mathrm{bs}}=2.50( \pm 0.772)^{3} \chi^{\mathrm{v}}+2.575( \pm 0.368) \text { eq. } .5 \\
& \mathrm{n}=10 \quad \mathrm{r}=0.753 \quad \mathrm{r}^{2}=0.567 \quad \mathrm{q}^{2}= \\
& 0.513 \mathrm{~s}=0.188 \quad \mathrm{~F}=10.492 \\
& \mathrm{pMIC}_{\mathrm{bs}}=1.681( \pm 0.823)^{3} \chi^{\mathrm{v}}+0.163( \pm 0.091) \log \mathrm{P}+2.365( \pm \\
& 0.347) \text { Eq. } 6 \\
& \mathrm{n}=10 \quad \mathrm{r}=0.839 \mathrm{r}^{2}=0.704 \quad \mathrm{q}^{2}=0.618 \\
& \mathrm{~s}=0.166 \quad \mathrm{~F}=8.30 \\
& \text { PRESS }=0.196 \quad \text { RMSE }=0.442
\end{aligned}
$$

In case of B. subtilis the developed QSAR model (Eq. 5) showed that there is a positive correlation between antibacterial activity of synthesized thiazole derivatives and their ${ }^{3} \chi^{\mathrm{v}}$ values. This is supported by antibacterial activity values of synthesized thiazole derivatives (Table 2) and their ${ }^{3} \chi^{v}$ values (Table 5). Further, during multiple linear regression (MLR) study there was a significant increment in $\mathrm{r}$ value on addition of $\log \mathrm{P}$ to ${ }^{3} \chi^{\mathrm{v}}$. $[\mathrm{r}=$ 0.753 (Eq. 5) to $r=0.839$ (Eq. 6)]. Topological indices parameters (e.g. ${ }^{1} \chi$ and ${ }^{3} \chi^{v}$ ) are numerical descriptors of a topology of a molecule. These are highly sensitive to bonding pattern, symmetry, content of heteroatom as well as degree of complexity of atomic neighborhoods. Since connectivity order of the constituent atoms in a molecule can be described by topological descriptors hence the information based upon connectivity can reveal the role of structural or sub-structural information of a molecule in estimating biological activity, viz. antimicrobial activity. Therefore, topological descriptors developed for predicting physicochemical properties and biological activities of chemical substance can be used for drug design (Lather and Madan, 2005).

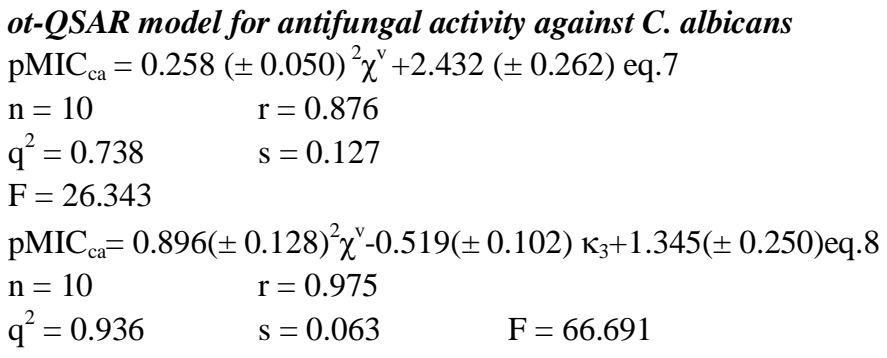

In case of $C$. albicans ${ }^{2} \chi^{\mathrm{v}}$ found to be the major factor influencing the antifungal activity (Eq. 7). Further, on combination of $\kappa_{3}$ with ${ }^{2} \chi^{\mathrm{v}}$, statistical more significant biparametric model was developed, as the value of $r$ increased from 0.876 (Eq. 7) to 0.975 (Eq. 8). Hence Eq. 8 has more predictability than Eq. 7, which can also be observed from low residual values (Table 8). Consequently, the topological parameter ${ }^{2} \chi^{\mathrm{v}}$ as well Kier's shape topological parameter, $\kappa_{3}$ playing a significant role in determining the activity of thiazole derivatives against $C$. albicans.

\section{ot-QSAR model for antifungal activity against $A$. niger $\mathrm{pMIC}_{\mathrm{an}}=0.123( \pm 0.018)^{2} \chi+2.770( \pm 0.162)$ eq.9 \\ $\mathrm{n}=12 \quad \mathrm{r}=0.922$ \\ $\mathrm{r}^{2}=0.850 \quad \mathrm{q}^{2}=0.831$ \\ $\mathrm{s}=0.093 \quad \mathrm{~F}=45.290$ \\ PRESS $=0.068 \quad$ RMSE $=0.261$}

The developed QSAR equation (Eq. 9) for A. niger depicted that second order connectivity index $\left({ }^{2} \chi\right)$ is positively correlated with antifungal activity of synthesized substituted thiazole derivatives. These results can be evidenced by high ${ }^{2} \chi$ values (9.97 and 10.76, Table 5) of compounds 11 and 12 having highest antifungal activity $\left(\mathrm{pMIC}_{\mathrm{an}}=4.23\right.$ and 4.01 , Table 2$)$ against $A$. niger, respectively.

The cross-validation of the developed models was performed by leave one out (LOO) method (Schaper, 1999). As per studies done by Golbraikh and Troposha for a valid QSAR model the value of cross validated $\mathrm{r}^{2}\left(\mathrm{q}^{2}\right)$ should be more than 0.5 (Golbraikh and Tropsha et al., 2002). Consequentially, all the QSAR models developed in present study are statistically valid and reliable in predicting the antimicrobial activity of synthesized thiazole derivatives. The plot of observed $\mathrm{pMIC}_{\mathrm{sa}} \mathrm{V}_{\mathrm{s}}$ predicted $\mathrm{pMIC}_{\mathrm{sa}}$ (Fig. 4) showed the accuracy of developed ot-QSAR model (Eq. 2).

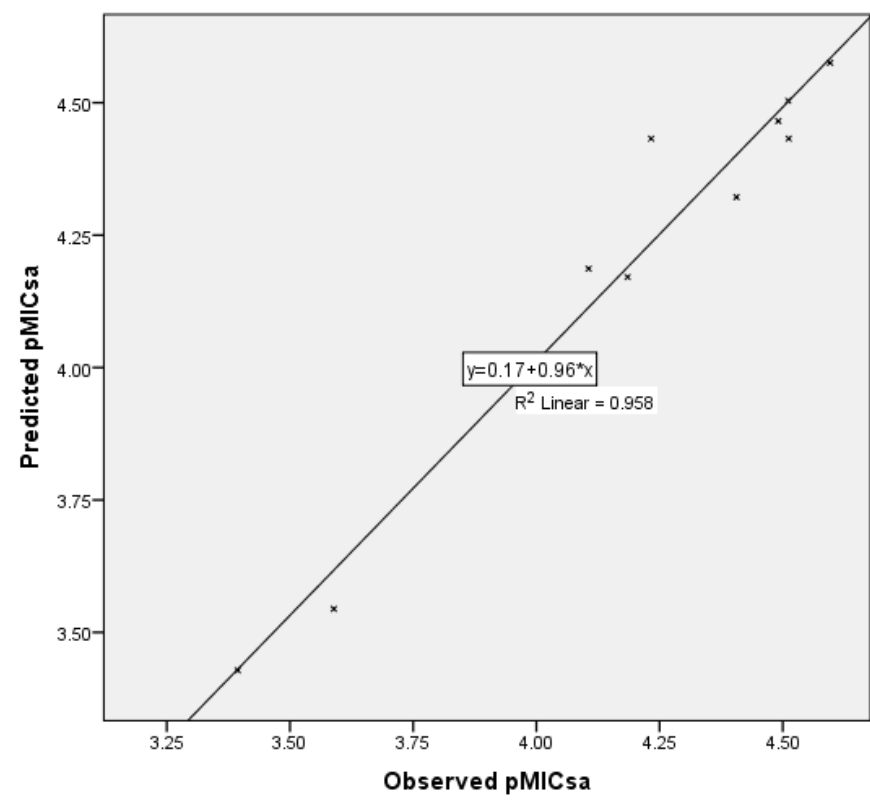

Fig. 4: Plot of observed $\mathrm{pMIC}_{\mathrm{sa}}$ values against predicted $\mathrm{pMIC}_{\mathrm{sa}}$ values for the multiple linear regression developed model by Eq. 2 
Table 7: Correlation of molecular descriptors with antimicrobial activity of synthesized thiazole derivatives

\begin{tabular}{|c|c|c|c|c|c|c|c|c|}
\hline Mol. Descriptor & pMIC $_{\text {bs }}$ & pMIC $_{\mathrm{sa}}$ & $\mathbf{p M I C}_{\mathrm{ec}}$ & $\mathbf{p M I C}_{\mathrm{ca}}$ & pMIC $_{\text {an }}$ & $\mathbf{p M I C}_{\mathrm{ab}}$ & $\mathbf{p M I C}_{\mathrm{af}}$ & pMIC $_{a m}$ \\
\hline $\log P$ & 0.725 & 0.832 & 0.832 & 0.691 & 0.733 & 0.854 & 0.745 & 0.843 \\
\hline MR & 0.722 & 0.937 & 0.937 & 0.844 & 0.867 & 0.937 & 0.896 & 0.950 \\
\hline${ }^{0} \chi$ & 0.739 & 0.930 & 0.930 & 0.874 & 0.912 & 0.936 & 0.935 & 0.962 \\
\hline${ }^{0} \chi^{\mathrm{v}}$ & 0.717 & 0.950 & 0.950 & 0.876 & 0.866 & 0.946 & 0.913 & 0.962 \\
\hline${ }^{n}{ }_{\chi}^{n}$ & 0.707 & 0.945 & 0.945 & 0.882 & 0.900 & 0.939 & 0.934 & 0.963 \\
\hline${ }^{1} \chi^{v}$ & 0.689 & 0.948 & 0.948 & 0.868 & 0.867 & 0.937 & 0.909 & 0.954 \\
\hline${ }^{2} \chi$ & 0.727 & 0.921 & 0.921 & 0.870 & 0.922 & 0.925 & 0.938 & 0.955 \\
\hline${ }^{2} \chi^{\mathrm{v}}$ & 0.714 & 0.950 & 0.950 & 0.876 & 0.889 & 0.945 & 0.925 & 0.965 \\
\hline${ }^{3} \chi$ & 0.696 & 0.630 & 0.630 & 0.632 & 0.775 & 0.684 & 0.734 & 0.719 \\
\hline${ }^{3} \chi^{v}$ & 0.753 & 0.797 & 0.797 & 0.783 & 0.853 & 0.833 & 0.856 & 0.863 \\
\hline$\kappa_{1}$ & 0.743 & 0.929 & 0.929 & 0.866 & 0.907 & 0.935 & 0.929 & 0.959 \\
\hline$\kappa_{2}$ & 0.707 & 0.930 & 0.930 & 0.842 & 0.875 & 0.927 & 0.899 & 0.944 \\
\hline$\kappa_{3}$ & 0.714 & 0.887 & 0.887 & 0.776 & 0.868 & 0.895 & 0.860 & 0.908 \\
\hline$\kappa \alpha_{1}$ & 0.728 & 0.930 & 0.930 & 0.871 & 0.893 & 0.933 & 0.924 & 0.956 \\
\hline$\kappa \alpha_{2}$ & 0.674 & 0.925 & 0.925 & 0.839 & 0.845 & 0.915 & 0.883 & 0.930 \\
\hline$\kappa \alpha_{3}$ & 0.686 & 0.890 & 0.890 & 0.780 & 0.843 & 0.890 & 0.850 & 0.901 \\
\hline $\mathrm{R}$ & 0.698 & 0.941 & 0.941 & 0.847 & 0.826 & 0.934 & 0.877 & 0.942 \\
\hline B & -0.438 & -0.870 & -0.870 & -0.840 & -0.773 & -0.809 & -0.847 & -0.843 \\
\hline W & 0.725 & 0.903 & 0.903 & 0.802 & 0.765 & 0.910 & 0.822 & 0.908 \\
\hline
\end{tabular}

Table 8: Comparison of observed and predicted antibacterial and antifungal activity obtained by ot-QSAR models

\begin{tabular}{|c|c|c|c|c|c|c|c|c|c|c|c|c|c|c|c|}
\hline \multirow[t]{2}{*}{ Comp. } & \multicolumn{3}{|c|}{ pMIC $_{\mathrm{sa}}$ MLR (Eq. 2) } & \multicolumn{3}{|c|}{ pMIC $_{\text {ec }}$ MLR (Eq. 4) } & \multicolumn{3}{|c|}{ pMIC $_{\text {bs }}$ MLR (Eq. 6) } & \multicolumn{3}{|c|}{ pMIC $_{\mathrm{ca}}$ MLR (Eq. 8) } & \multicolumn{3}{|c|}{ pMIC $_{\text {an }}$ (Eq. 9) } \\
\hline & Obs. & Pre. & Res. & Obs. & Pre. & Res. & Obs. & Pre. & Res. & Obs. & Pre. & Res. & Obs. & Pre. & Res. \\
\hline 2 & 3.43 & 3.39 & -0.03 & 3.43 & 3.39 & -0.03 & 3.29 & 3.39 & 0.10 & 3.33 & 3.39 & 0.06 & 3.39 & 3.39 & 0.00 \\
\hline 3 & 4.32 & 4.41 & 0.08 & 4.32 & 4.41 & 0.08 & 3.74 & 3.79 & 0.05 & 3.87 & 3.79 & -0.08 & 3.81 & 3.79 & -0.02 \\
\hline 4 & 4.43 & 4.51 & 0.08 & 4.43 & 4.51 & 0.08 & 3.92 & 3.93 & 0.01 & 3.88 & 3.93 & 0.05 & 4.00 & 3.93 & -0.07 \\
\hline 5 & 4.47 & 4.49 & 0.03 & 4.47 & 4.49 & 0.03 & 3.80 & 3.89 & 0.09 & 3.94 & 3.89 & -0.05 & 3.91 & 3.89 & -0.02 \\
\hline 6 & 4.17 & 4.18 & 0.01 & 4.17 & 4.18 & 0.01 & 3.85 & 3.87 & 0.02 & 3.60 & 3.57 & -0.03 & 3.91 & 3.87 & -0.04 \\
\hline 7 & 4.19 & 4.11 & -0.08 & 4.19 & 4.11 & -0.08 & 3.61 & 3.20 & -0.41 & 3.76 & 3.81 & 0.05 & 3.81 & 3.81 & 0.00 \\
\hline 8 & 4.50 & 4.51 & 0.01 & 4.50 & 4.51 & 0.01 & 3.93 & 3.92 & -0.01 & 3.94 & 3.92 & -0.03 & 3.93 & 3.92 & -0.01 \\
\hline 10 & 3.54 & 3.59 & 0.04 & 3.54 & 3.59 & 0.04 & 3.49 & 3.59 & 0.10 & 3.35 & 3.29 & -0.06 & 3.58 & 3.59 & 0.01 \\
\hline 11 & 4.43 & 4.23 & -0.20 & 4.43 & 4.23 & -0.20 & 3.92 & 3.93 & 0.01 & 3.88 & 3.93 & 0.05 & 4.00 & 4.23 & 0.23 \\
\hline 12 & 4.58 & 4.60 & 0.02 & 4.58 & 4.60 & 0.02 & 4.00 & 4.01 & 0.01 & 3.95 & 4.01 & 0.06 & 4.09 & 4.01 & -0.08 \\
\hline
\end{tabular}

Table 9: Comparison of observed and predicted antimicrobial activity obtained by $m t$-QSAR models.

\begin{tabular}{|c|c|c|c|c|c|c|c|c|c|}
\hline \multirow[t]{2}{*}{ Comp. } & \multicolumn{3}{|c|}{ pMIC $_{a b}$ (Eq. 10) } & \multicolumn{3}{|c|}{ pMIC $_{\text {af }}$ MLR (Eq. 12) } & \multicolumn{3}{|c|}{ pMIC $_{a m}$ MLR (Eq. 13) } \\
\hline & Obs. & Pre. & Res. & Obs. & Pre. & Res. & Obs. & Pre. & Res. \\
\hline 2 & 3.38 & 3.39 & 0.02 & 3.34 & 3.39 & 0.05 & 3.39 & 3.39 & 0.01 \\
\hline 3 & 4.02 & 4.20 & 0.18 & 3.77 & 3.79 & 0.03 & 4.04 & 4.04 & 0.00 \\
\hline 4 & 4.24 & 4.32 & 0.08 & 3.98 & 3.93 & -0.05 & 4.14 & 4.16 & 0.02 \\
\hline 5 & 4.18 & 4.29 & 0.12 & 3.86 & 3.89 & 0.03 & 4.11 & 4.13 & 0.02 \\
\hline 6 & 4.18 & 4.08 & -0.10 & 3.76 & 3.72 & -0.03 & 3.97 & 3.94 & -0.03 \\
\hline 7 & 4.02 & 3.80 & -0.22 & 3.77 & 3.81 & 0.04 & 3.90 & 3.80 & -0.10 \\
\hline 8 & 4.26 & 4.31 & 0.05 & 3.86 & 3.92 & 0.05 & 4.07 & 4.16 & 0.09 \\
\hline 10 & 3.59 & 3.59 & 0.00 & 3.56 & 3.44 & -0.12 & 3.50 & 3.53 & 0.03 \\
\hline 11 & 4.24 & 4.13 & -0.10 & 3.98 & 4.08 & 0.10 & 4.14 & 4.11 & -0.03 \\
\hline 12 & 4.39 & 4.40 & 0.01 & 4.07 & 4.01 & -0.07 & 4.22 & 4.24 & 0.02 \\
\hline
\end{tabular}

To examine the presence of a systemic error in developed QSAR equation (Eq. 2), the observed $\mathrm{pMIC}_{\mathrm{sa}}$ values were plotted against the residuals $\mathrm{pMIC}_{\mathrm{sa}}$ values (Fig. 5). The presence of the residual points on both sides of zero indicated that no systemic error exists in the development of QSAR model. (Golbraikh and Tropsha et al., 2002). Usually for QSAR analysis, the biological activity data of synthesized molecules should lies in between 2-3 orders of magnitude. Although, in present study the range of antimicrobial activities of synthesized thiazole derivatives is within one order of magnitude, though the low residual values (Table 8) evidenced the high predictability of developed QSAR models (Eqs. 1-9). This is in agreement with results suggested by earlier studies (Narasimhan et al., 2007; Sharma et al., 2006; Hatya et al.,
2006; Kumar et al., 2006), which confirmed that the robustness of the QSAR model lies in its predictive ability, although the biological activity data existed in narrow range of magnitude. Moreover, Kim et al. (2007) recommended that developed QSAR models are acceptable if the value of standard deviation is not much higher than 0.3 . Hence, the above facts justify the statistical acceptability of developed QSAR models (Eqs. 1-9).

\section{Development of multi-target QSAR model (mt-QSAR)}

Aforementioned $o t$-QSAR models showed that five different equations have to be used to predict the activity of synthesized derivatives against the respective bacterial and fungal strains. But results of our earlier studies recommended that use of 


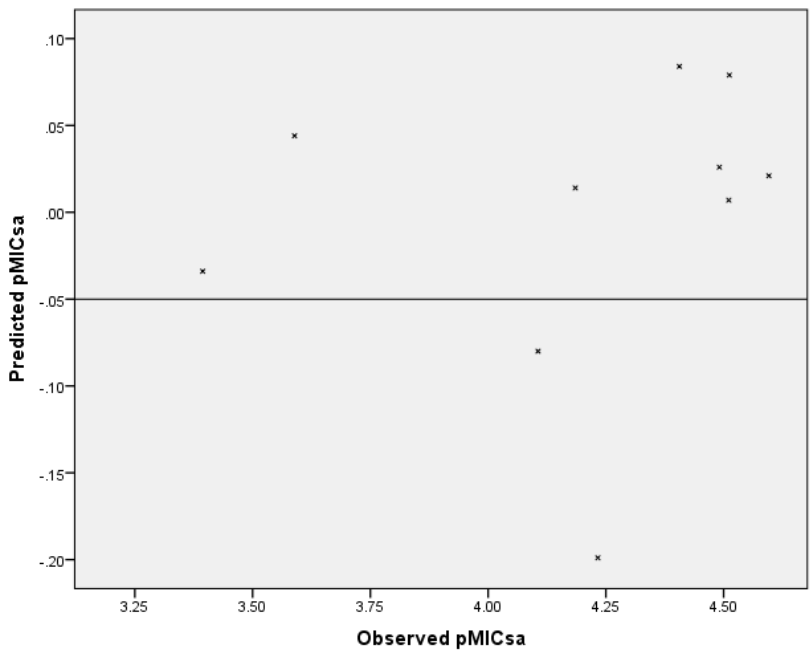

Fig. 5: Plot of observed $\mathrm{pMIC}_{\mathrm{sa}}$ values against residual $\mathrm{pMIC}_{\mathrm{sa}}$ values for the multiple linear regression developed model by Eq. 2

$o t$-QSAR equations is not much practicable, when we have to predict the activity of synthesized compounds against more than one target. As different ot-QSAR equations have to be used for different targets. Above facts inspired us to develop multi-target QSAR ( $m t$ - QSAR) models. In contrast to ot-QSAR, the $m t$-QSAR model is a single equation that considers common and essential physicochemical parameters for describing the antimicrobial activity for different targets (Prado -Prado et al., 2008; Gonzalez-Diaz et al., 2007, 2008a; Gonzalez-Diaz and PradoPrado 2008; Cruz-Monteagudo et al., 2007).

In the present study we have attempted to develop three different types of $m t$-QSAR models viz. $m t$-QSAR model for describing antibacterial activity of synthesized compounds against S. aureus, B. subtilis and E. coli, $m t$-QSAR model for describing antifungal activity of synthesized compounds against $C$. albicans and $A$. niger as well a common $m t$-QSAR model for describing the antimicrobial (overall antibacterial and antifungal) activity of synthesized thiazole derivatives against all the above mentioned microorganisms. In order to build up $m t$-QSAR equations, firstly we have calculated the average antibacterial, antifungal and antimicrobial activities values of synthesized thiazole derivatives which are presented in Table 2. Further, these average antimicrobial activity values were interrelated with the physicochemical parameters (Table 5) of synthesized compounds.

\section{mt-QSAR model for antibacterial activity}

$$
\begin{aligned}
& \mathrm{pMIC}_{\mathrm{ab}}=0.163( \pm 0.021)^{1} \chi+2.422( \pm 0.214) \\
& \mathrm{n}=12 \quad \mathrm{r}=0.938 \quad \mathrm{r}^{2}=0.880 \quad \mathrm{q}^{2}=0.868 \\
& \mathrm{~s}=0.125 \quad \mathrm{~F}=59.934 \\
& \text { PRESS }=0.124 \quad \text { RMSE }=0.352
\end{aligned}
$$

In case of $m t$-QSAR model for antibacterial activity revealed the significance of first order molecular connectivity index $\left({ }^{1} \chi\right)$ in describing antibacterial activity of synthesized thiazole derivatives. Positive coefficient of ${ }^{1} \chi$ in developed model (Eq. 10) implies that antibacterial activity is directly proportional to value of ${ }^{1} \chi$. This can be proved by high antibacterial values of compounds $\mathbf{4}, \mathbf{8}$ and $\mathbf{1 2}\left(\mathrm{pMIC}_{\mathrm{ab}}=4.32,4.31\right.$ and 4.40, respectively) having high values of ${ }^{1} \chi$ i.e. $11.13,11.30$ and 12.06 (Table 5), respectively.

\section{mt-QSAR model for antifungal activity}

$$
\begin{aligned}
& \mathrm{pMIC}_{\mathrm{af}}=0.124( \pm 0.160)^{2} \chi+2.713( \pm 0.144) \quad \text { eq11 } \\
& \mathrm{n}=12 \quad \mathrm{r}=0.938 \quad \mathrm{r}^{2}=0.880 \quad \mathrm{q}^{2}=0.865 \\
& \mathrm{~s}=0.083 \quad \mathrm{~F}=58.803 \\
& \mathrm{pMIC}_{\mathrm{af}}=0.210( \pm 0.057)^{2} \chi-0.144( \pm 0.092) \kappa_{3}+2.570( \pm 0.161) \text { eq. } 12 \\
& \mathrm{n}=12 \quad \mathrm{r}=0.954 \quad \mathrm{r}^{2}=0.910 \quad \mathrm{q}^{2}=0.885 \\
& \mathrm{~s}=0.076 \quad \mathrm{~F}=35.79 \\
& \text { PRESS }=0.041 \quad \text { RMSE }=0.203
\end{aligned}
$$

In case of $m t$-QSAR model for antifungal activity second order molecular connectivity index $\left({ }^{2} \chi\right)$ was found to significant (Eq. 11). Once again the positive coefficient of molecular connectivity index directly correlates with antifungal activity. Further, as we go for development of biparametric models the combination ${ }^{2} \chi$ and $\kappa_{3}$ produced statistically more significant equation (Eq. 12) which led to small increase in values of $r[0.938$, Eq. (11) to 0.954, Eq. (12)] and $\mathrm{q}^{2}$ [0.865, Eq. (11) to 0.885, Eq. (12)] and lowering in value of standard deviation [0.083, Eq. (11) to 0.076 , Eq. (12)].

\section{mt-QSAR model for antibacterial activity}

$\mathrm{pMIC}_{\mathrm{am}}=0.654( \pm 0.105)^{2} \chi^{\mathrm{v}}-0.337( \pm 0.106) \kappa \alpha_{3}+1.756( \pm$

$0.195)$ eq13

$$
\begin{array}{llll}
\mathrm{n}=12 & \mathrm{r}=0.986 & \mathrm{r}^{2}=0.972 & \mathrm{q}^{2}=0.963 \\
\mathrm{~s}=0.055 & \mathrm{~F}=119.646 & & \\
\text { PRESS }=0.022 & \text { RMSE }=0.145 & &
\end{array}
$$

Further, in case of $m t$-QSAR model for overall antimicrobial activity when we go for development of biparametric model, statistically most significant and predictable equation was obtained by combining $\kappa \alpha_{3}$ and ${ }^{2} \chi^{\mathrm{v}}$ (Eq. 13), which can be confirmed by low residual values (Table 9). Moreover, the developed model predicts $96.3 \%$ and explains $98.6 \%$ variances of antimicrobial activity.

The plot of observed $\mathrm{pMIC}_{\mathrm{am}}$ Vs predicted $\mathrm{pMIC}_{\mathrm{am}}$ (Fig. 6) showed the accuracy of developed $m t$-QSAR model (Eq. 13). Additionally there is no systemic error in developed model (Eq. 13), which can be confirmed by plot of residual $\mathrm{pMIC}_{\mathrm{am}} \mathrm{Vs}$ observed $\mathrm{pMIC}_{\mathrm{am}}$ (Fig. 7) as the residual error values are present on both side of zero. Moreover, the small residual values of all tested bacterial and fungal strains presented in Table 8 and 9 were in concurrence with model expressed by Eq. 2, 4, 6, 8, 9, 10, 12 and 13. From the aforementioned QSAR models, it can be concluded that the molecular connectivity index and Kier's shape index, are key parameters for the antimicrobial activity of synthesized thiazole derivatives and can be cosidered as important factors for interaction with target site of different microorganisms. Moreover, $m t$-QSAR models found be statistically more significant in describing antimicrobial activity of synthesized thiazole derivatives than $o t$-QSAR models. 


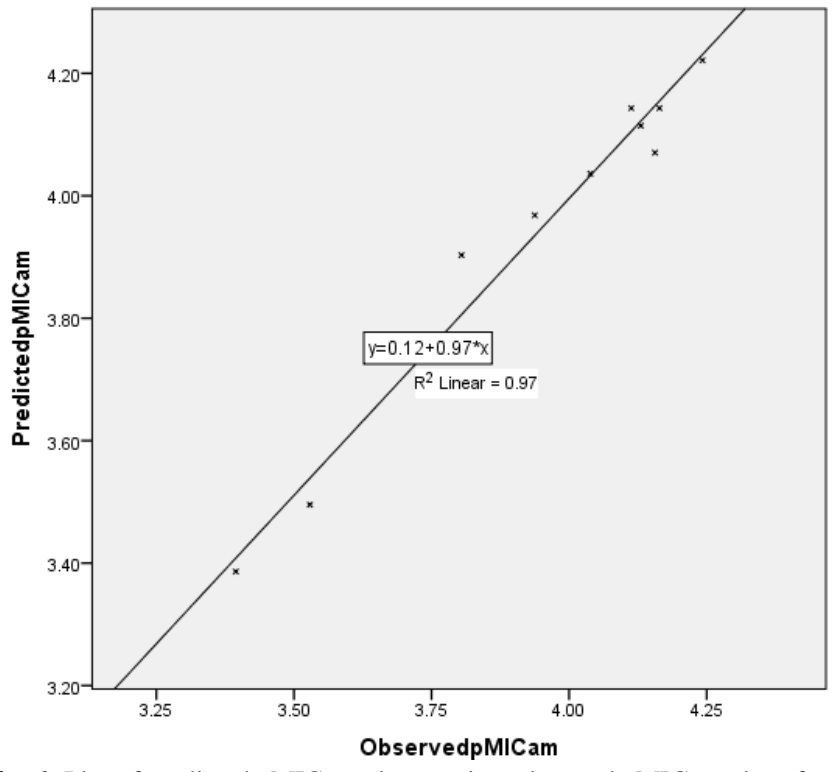

Fig. 6: Plot of predicted $\mathrm{pMIC}$ am values against observed $\mathrm{pMIC}_{\mathrm{am}}$ values for the MLR developed model by Eq. 13

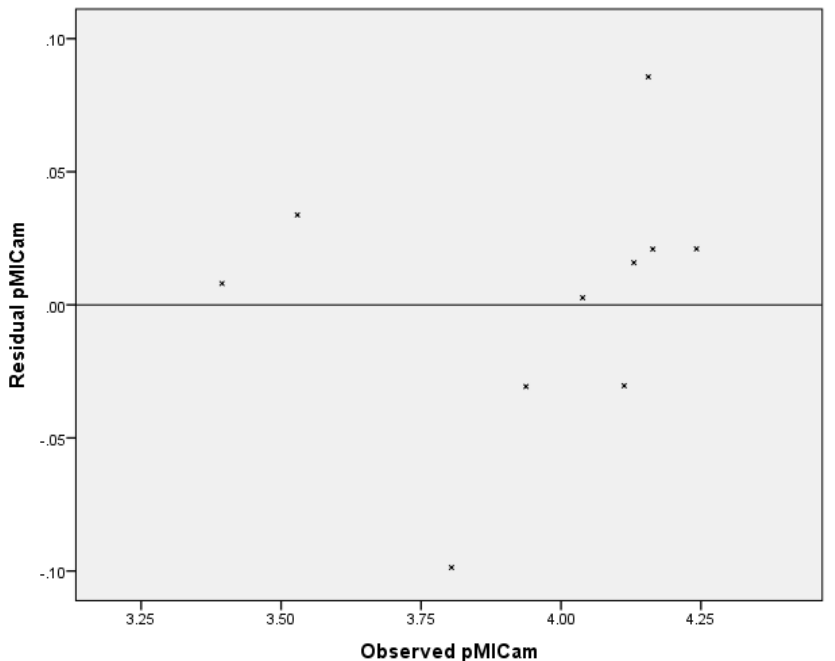

Fig. 7: Plot of residual $\mathrm{pMIC}_{\mathrm{am}}$ values against residual $\mathrm{pMIC}_{\mathrm{am}}$ values for the MLR developed model by Eq. 13.

\section{CONCLUSION}

In present study, $N$-(4-phenyl-thiazol-2-yl)benzamide/amide derivatives (3-7, 9 and 11-12) and (3,4dimethoxy-benzylidene)-(4-phenyl-thiazol-2-yl)-amine (8) have been synthesized (Scheme 1 and 2) successfully in appreciable yields and evaluated for their in vitro antibacterial and antifungal activities against $B$. subtilis, E. coli, $S$. aureus, $C$. albicans and $A$. niger by tube dilution method. Chemical structures of synthesized compounds were ascertained on the basis of their spectral data (IR and ${ }^{1} \mathrm{H}$ NMR). The analysis of antimicrobial activity results indicated that the presence of $\mathrm{NO}_{2}$ and $\mathrm{OCH}_{3}$ groups at para position of phenyl ring improved the antimicrobial activity of the synthesized thiazole derivatives. The replacement of $\mathrm{NH}_{2}$ group (2) with substituted phenyl ring (3-8 and 11-12) led to a noticeable increase in antimicrobial activity of the synthesized compounds against S. aureus and E. coli. Molecular docking studies revealed that compounds $\mathbf{1 1}$ and $\mathbf{1 2}$ is showing excellent binding score of $9.2 \mathrm{kcal} / \mathrm{mol}$ and $-9.1 \mathrm{kcal} / \mathrm{mol}$, respectively as the nitro head group at para position is making strong hydrogen bonding interaction with Arg383, Arg173, Glu396 and Gln346 amino acid residues. These compounds also have potential to show sandwich type $\pi$-stacking interactions. Further, QSAR studies indicated that the molecular connectivity index $\left({ }^{2} \chi^{v}\right)$ and Kier's shape index $\left(\kappa \alpha_{3}\right)$ are key parameters for the antimicrobial activity of synthesized thiazole derivatives. The developed QSAR equations satisfy the statistical validation criteria to a considerable extent and can be a valuable theoretical base for proposing more potent 2,4disubstituted thiazole derivatives.

\section{REFERENCES}

Balaban AT. Highly discriminating distance based topological indices. Chem Phys Lett, 1982; 89:399-404.

Ban M, Taguchi H, Katsushima T, Takahashi M, Shinoda K, Watanabe A, Tominaga T. Novel antiallergic and antiinflammatory agents. Part I: Synthesis and pharmacology of glycolic amide derivatives. Bioorg Med Chem, 1998; 6:1069-1076.

Bates CJ, Adams WR, Handschumacher RE. Control of the formation of uridine diphospho- $N$-acetyl-hexosamine and glycoprotein synthesis in rat liver. J Biol Chem, 1966; 241:1705-1712.

Bharti SK, Nath G, Tilak R, Singh SK. Synthesis, anti-bacterial and anti-fungal activities of some novel Schiff bases containing 2,4disubstituted thiazole ring. Eur J Med Chem, 2010; 42:651-660.

Cappucino JG, Sherman N, 1999, Microbiology-a laboratory manual, Addison Wesley Longman Inc, California, 263.

Chmara H, Andruszkiewicz R, Borowski E, Inactivation of glucosamine-6-phosphate synthetase from Salmonella typhimurium LT 2 SL 1027 by $\mathrm{N}$ beta-fumarylcarboxyamido-L-2,3-diamino-propionic acid. Biochem Biophys Res Commun, 1984; 120:865-872.

Chmara H, Andruszkiewicz R, Borowski E. Inactivation of glucosamine-6-phosphate synthetase from Salmonella typhimurium LT2 by fumaroyl diaminopropanoic acid derivatives, a novel group of glutamine analogs. Biochim Biophys Acta, 1986; 870:357-366.

Cohen A, Verhaeghe P, Crozet MD, Hutter S, Rathelot P, Vanelle $\mathrm{P}$, Azas $\mathrm{N}$ Tandem synthesis and in vitro antiplasmodial evaluation of new naphtho[2,1-d] thiazole derivatives Eur $\mathbf{J}$ Med Chem, 2012; 55:315-324.

Cruz-Monteagudo M, Gonzalez-Diaz H, Aguero-Chapin G, Santana L, Borges F, Dominguez ER, Podda G, Uriarte E. Computational chemistry development of a unified free energy Markov model for the distribution of 1300 chemicals to 38 different environmental or biological systems. J Comput Chem, 2007; 28(11):1909-1923.

Dutka-Malen S, Mazodier P, Badet B. Molecular cloning and overexpression of the glucosamine synthetase gene from Escherichia coli. Biochimie, 1988; 70:287-290.

El-Sabbagh OI, Baraka MM, Ibrahim SM, Pannecouque C, Andrei G, Snoeck R, Balzarini J, Rashad AA. Synthesis and antiviral activity of new pyrazole and thiazole derivatives. Eur J Med Chem, 2009; 44: 3746-3753.

Golbraikh A, Tropsha A. Beware of $q^{2}$ !. J Mol Graphics Model, 2002; 20(4):269-276.

Gonzalez-Diaz H, Gonzalez-Diaz Y, Santana L, Ubeira FM, Uriarte E. Networks and connectivity indices. Proteomics, 2008a; 8(4): 750-778.

Gonzalez-Diaz H, Prado-Prado FJ. Unified QSAR and networkbased computational chemistry approach to antimicrobials, part 1: Multi species activity models for antifungals. J Comput Chem, 2008; 29(4):656667.

Gonzalez-Diaz H, Vilar S, Santana L, Uriarte E. Medicinal chemistry and bioinformatics-current trends in drugs discovery with networks topological indices. Curr Top Med Chem, 2007; 7(10):10151029. 
Hansch C, Fujita T. $p-\sigma-\pi$ Analysis. A method for the correlation of biological activity and chemical structure. J Am Chem Soc, 1964; 86:1616-1626.

Hansch C, Leo A, Unger SH, Kim KH, Nikaitani D, Lien EJ. Aromatic substituent constants for structure- activity correlations. J Med Chem, 1973; 16:1207-1216.

Hatya SA, Aki-Sener E, Tekiner-Gulbas B, Yildiz I, TemizArpaci O, Yalcin I, Altanlar N. Synthesis, antimicrobial activity and QSARs of new benzoxazine-3-ones. Eur J Med Chem, 2006; 41:13981404.

Helal MHM, Salem MA, El-Gaby MSA, Aljahdali M. Synthesis and biological evaluation of some novel thiazole compounds as potential anti-inflammatory agents Eur J Med Chem, 2013; 65:517-526.

Hyperchem 6.0, Hypercube, Inc., Gainesville, 1993.

Jain A, Pandey V, Ganeshpurkar A, Dubey N, Bansal D. Formulation and characterization of floating microballoons of Nizatidine for effective treatment of gastric ulcers in murine model. Drug Deliv, 2014 DOI:10.3109/10717544.2014.891273.

Kier LB, Hall LH. 1976, Molecular connectivity in chemistry and drug research, New York: Academic Press, 79-82.

Kim Y, Farrah S, Baney RH. Structure-antimicrobial activity relationship for silanols, a new class of disinfectants, compared with alcohols and phenols. Int J Antimicrob Ag, 2007; 29:217-222.

Kumar A, Sharma P, Gurram VK, Rane N. Studies on synthesis and evaluation of quantitative structure-activity relationship of phosphorus 10-methyl-6-oxo-5-arylazo-6,7-dihydro-5H $(1,3)$ azaphospholo (1,5-d) (1,4) benzodiazepin-2-phospha-3-ethoxycarbonyl-1-phosphorus dichlorides. Bioorg Med Chem Lett, 2006; 16:2484-2491.

Kumar D, Judge V, Narang R, Sangwan S, Clerq E. De, Balzarini J, Narasimhan B. Benzylidene/2-chlorobenzylidene hydrazides: Synthesis, antimicrobial activity, QSAR studies and antiviral evaluation. Eur J Med Chem, 2010; 45:2806-2816.

Kumar P, Narasimhan B, Sharma D, Judge V, Narang R. Hansch analysis of substituted benzoic acid benzylidene/furan-2ylmethylene, hydrazides as antimicrobial agents. Eur J Med Chem, 2009; 44: 1853-1863.

Lather V, Madan AK. Topological models for the prediction of anti-HIV activity of dihydro (alkylthio) (naphthylmethyl) oxopyrimidines. Bioorg Med Chem, 2005, 13:1599-1604.

Milewski S, Chmara H, Andruszkiewicz R, Borowski E, Zaremba M, Borowski. Antifungal peptides with novel specific inhibitors of glucosamine 6-phosphate synthase. Drugs Exp Clin Res, 1988; 14:461465 .

Mjambili F, Njoroge M, Naran K, Kock CD, Smith PJ, Mizrahi V, Warner D, Chibale K. Synthesis and biological evaluation of 2aminothiazole derivatives as antimycobacterial and antiplasmodial agents Bioorg Med Chem Lett, 2014; 24:560-564

Mohsen S, Razieh S, Maryam BZ, Behzad MF, Reza AK. QSAR study of anthranilic acid sulfonamides as inhibitors of methionine aminopeptidase-2 using LS-SVM and GRNN based on principal components. Eur J Med Chem, 2010; 45:4499-4508.

Narang R, Narasimhan B, Sharma S, (Naphthalen-1-yloxy)acetic acid benzylidene/(1-phenyl-ethylidene)-hydrazide derivatives: Synthesis, antimicrobial evaluation and QSAR studies. Med Chem Res, 2012; 21:2526-2547.

Narang R, Narasimhan B, Sharma S, Sriram D, Yogeeswari P, Clercq ED, Balzarini J, Nicotinic acid benzylidene hydrazides: Synthesis, antitubercular, antiviral, antimicrobial evaluation and QSAR studies. Med Chem Res, 2012; 21:1557-1576.

Narang R, Narasimhan B, Sharma S, Sriram D, Yogeeswari P, Clercq ED, Balzarini J, Nicotinic acid benzylidene/phenyl-ethylidene hydrazides: Synthesis, antitubercular, antiviral, antimicrobial evaluation and QSAR studies. Lett Drug Design and Discov, 2011; 8:733-749.

Narang R, Narasimhan B, Sharma S, Sriram D., Yogeeswari P, Clercq ED, Balzarini J, Substituted naphthalen-1-yl-acetic acid benzylidene/(1-phenyl-ethylidene)-hydrazides: synthesis, antiviral, antibacterial and antifungal evaluation and QSAR analysis. Med Chem, 2013; 9:249-74.
Narasimhan B, Judge V, Narang R, Ohlan S, Ohlan R. Quantitative structure activity relationship studies for prediction of antimicrobial activity of synthesized 2,4-hexadienoic acid derivatives. Bioorg Med Chem Lett, 2007; 21:5836-5845.

Narasimhan B, Ohlan S, Ohlan R, Judge V, Narang R. Hansch analysis of veratric acid derivatives as antimicrobial agents. Eur $\mathrm{J}$ Med Chem, 2009; 44:689-700.

Nishikaku F, Koga Y, Suppression of murine collagen-induced arthritis by treatment with a novel thiazole derivative, SM-8849. Immunopharmacology, 1993; 25:65-74.

Novakova I, Subileau EA, Toegel S, Gruber D, Lachmann B, Urban E, Chesne C, Noe CR, Neuhaus W. Transport rankings of nonsteroidal antiinflammatory drugs across blood-brain barrier in vitro models. PLoS One, 2014; 9:e86806.

Oltulu O, Yasar MM, Eroglu EA. QSAR study on relationship between structure of sulfonamides and their carbonic anhydrase inhibitory activity using the eigenvalue (EVA) method. Eur J Med Chem, 2009; 44:3439-344.

Ozdemir A, Turan-Zitouni G, Kaplancikli ZA, Revial G, Güven K. Synthesis and antimicrobial activity of 1-(4-aryl-2-thiazolyl)-3-(2thienyl)-5-aryl-2-pyrazoline derivatives. Eur J Med. Chem 2007; 42:403409.

Perez KK, Olsen RJ, Musick WL, Cernoch PL, Davis JR, Peterson LE, Musser JM. Integrating rapid diagnostics and antimicrobial stewardship improves outcomes in patients with antibiotic resistant Gramnegative bacteremia. J Infect, 2014; 69:216-225.

Pharmacopoeia of India, Controller of Publications, Ministry of Health Department, Govt. of India, New Delhi, 2007; I:37.

Popsavin M, Torovic L, Svircev M, Kojic V, Bogdanovic G, Popsavin V. Synthesis and antiproliferative activity of two new tiazofurin analogues with 2'-amido functionalities. Bioorg Med Chem Lett, 2006; 16:2773-2776.

Prado-Prado FJ, Gonzalez-Diaz H, de la Vega OM, Ubeira FM, Chou KC. Unified QSAR approach to antimicrobials. Part 3: First multitasking QSAR model for Input-Coded prediction, structural backprojection, and complex networks clustering of antiprotozoal compounds. Bioorgan Med Chem, 2008; 16(11):5871-5880.

Rahmutulla B, Matsushita K, Satoh M, Seimiya M, Tsuchida S, Kubo S, Shimada H, Ohtsuka M, Miyazaki M, Nomura F. Alternative splicing of FBP-interacting repressor coordinates c-Myc, P27Kip1/cyclinE and Ku86/XRCC5 expression as a molecular sensor for bleomycininduced DNA damage pathway. Oncotarget, 2014; 15:2404-2417.

Randic M. Comparative Regression Analysis-Regressions Based on Single Descriptor. Croat Chem Acta, 1993; 66:289-312.

Randic M. On the Characterization of Molecular Branching. J Am Chem Soc, 1975; 97:6609-6615.

Sarojini BK, Krishna BG, Darshanraj CG, Bharath BR, Manjunatha H. Synthesis, characterization, in vitro and molecular docking studies of new 2,5-dichloro thienyl substituted thiazole derivatives for antimicrobial properties. Eur J Med Chem, 2010; 45:3490-3496.

Schaper KJ. Free-Wilson-type analysis of non-additive substituent effects on THPB dopamine receptor affinity using artificial neural networks. Quant Struct Act Relat, 1999; 18:354-360

Sevrioukova IF, Poulos TL. Dissecting cytochrome P450 3A4ligand interactions using ritonavir analogues. Biochemistry, 2013;52: 4474-4481.

Sharma P, Kumar A, Sharma M. Synthesis and QSAR studies on 5-(2-(2-methylprop-1-enyl)-1H-benzimidazol-1yl)-4,6-diphenylpyrimidin-2-(5H)- thione derivatives as antibacterial. Eur J Med Chem, 2006; 41:833-840.

Sharma P, Rane N, Gurram VK. Synthesis and QSAR studies of pyrimido(4,5-d)pyrimidine-2,5-dione derivatives as potential antimicrobial agents. Bioorg Med Chem Lett, 2004; 14:4185-4190.

Shoichet BK, McGovern SL, Wei B, Irwin JJ. Lead discovery using molecular docking, Curr Opin Chem Bio, 2002; 6(4): 439-446.

Singh S, Wanjari PJ, Bhatia S, Sonwane VC, Chakraborti AK, Bharatam PV. Design, synthesis, biological evaluation and toxicity studies of $N, N$-disubstituted biguanides as quorum sensing inhibitors. Med Chem Res, 2014. DOI 10.1007/s00044-014-1255-y. 
Soares MI, Brito AF, Laranjo M, Paixao JA, Botelho MF, Melo TMVDP. Chiral 6,7-bis(hydroxymethyl)-1H,3H-pyrrolo[1,2-c]thiazoles with anti-breast cancer properties. Eur J Med Chem, 2013; 60:254-262.

Sortino M, Delgado P, Jaurez S, Quiroga J, Abonia R, Insuasey B, Nogueras M, Rodero, L. Synthesis and antifungal activity of (Z)-5arylidenerhodanines. Bioorg Med Chem Lett, 2007; 15:484-494.

SPSS for Windows, version 10.05, SPSS Inc., Bangalore, India 1999.

Styrt B, Rocklin RE, Klempner MS. Inhibition of neutrophil superoxide production by fanetizole. Inflammation. 1985; 9:233-244.

Trott O, Olson AJ. AutoDock Vina: improving the speed and accuracy of docking with a new scoring function, efficient optimization and multithreading, J Comput Chem, 2010; 31:455-461.

TSAR 3D Version 3.3, Oxford Molecular Limited, 2000.

Wei L, Cheng J, Meng Y, Ren Y, Deng H, Guo Y. A novel formulation of thiamine dilaurylsulphate and its preservative effect on apple juice and sterilised milk. Food Chem, 2014; 1:415-422.

Wiener H. Structural determination of paraffin boiling points. J Am Chem Soc, 1947; 69:17-20.
Ye J, Liu Q, Wang C, Meng Q, Sun H, Peng J, Ma X, Liu K. Benzylpenicillin inhibits the renal excretion of acyclovir by OAT1 and OAT3. Pharmacol Rep, 2013; 65:505-512.

Zablotskaya A, Segal I, Geronikaki A, Tatiana E, Belyakov S, Petrova M, Shestakova I, Zvejniece L, Nikolajeva V. Synthesis, physicochemical characterization, cytotoxicity, antimicrobial, antiinflammatory and psychotropic activity of new N-[1,3-(benzo)thiazol-2yl]- $\omega$-[3,4-dihydroisoquinolin-2(1H)-yl]alkanamides. Eur J Med Chem, 2013; 70:846-856.

\section{How to cite this article:}

Preeti Arora, Rakesh Narang, Sonam Bhatia, Surendra Kumar Nayak, Sachin Kumar Singh, Balasubramanian Narasimhan. Synthesis, molecular docking and QSAR studies of 2, 4disubstituted thiazoles as antimicrobial agents. J App Pharm Sci, 2015; 5 (02): 028-042. 